\title{
Phytochemical analysis of Acacia nilotica and evaluation of its antileishmanial potential
}

\section{Rahat Ali}

Jamia Millia Islamia

Shams Tabrez

Jamia Millia Islamia

Fazlur Rahman

Jamia Millia Islamia

Abdulaziz Alouffi

King Abdulaziz City for Science and Technology

Bader Alshehri

Majmaah University

Fahdah Alshammari

Northern Border University

Mohammed Alaidarous

Majmaah University

Saeed Banawas

Majmaah University

Abdul Aziz Dukhyil

Majmaah University

Abdur Rub ( $\square$ arub@jmi.ac.in )

Jamia Millia Islamia

\section{Research Article}

Keywords: Leishmania, Acacia nilotica, antileishmanial, drugs, host, infection, in silico

Posted Date: January 21st, 2021

DOI: https://doi.org/10.21203/rs.3.rs-120320/v2

License: (1) This work is licensed under a Creative Commons Attribution 4.0 International License.

Read Full License 


\title{
Phytochemical analysis of Acacia nilotica and evaluation of its antileishmanial potential
}

${\text { Rahat } \text { Ali }^{a} \text {, Shams Tabrez }}^{a}$, Fazlur Rahman ${ }^{a}$, Abdulaziz S. Alouffi $^{\mathrm{b}}$, Bader Mohammed

Alshehri $^{\mathrm{c}}$, Fahdah Ayed Alshammari ${ }^{\mathrm{d}}$, Mohammed A. Alaidarous ${ }^{\mathrm{c}, \mathrm{e}}$, Saeed Banawas ${ }^{\mathrm{c}, \mathrm{e}, \mathrm{f}}$, Abdul Aziz Bin Dukhyil ${ }^{\mathrm{c}}$, Abdur Rub ${ }^{a *}$

${ }^{a}$ Infection and Immunity Lab (414), Department of Biotechnology, Jamia Millia Islamia (A Central University), New Delhi, India-110025, ${ }^{b}$ King Abdulaziz City for Science and Technology, Riyadh, KSA, ${ }^{c}$ Department of Medical Laboratory Sciences, College of Applied Medical Sciences, Majmaah University, Al Majmaah, 11952, Saudi Arabia. ${ }^{d}$ College of Sciences and Literature Microbiology, Nothern Border University, KSA, ${ }^{e}$ Health and Basic Sciences Research Center, Majmaah University, Al Majmaah, Saudi Arabia, ${ }^{f}$ Department of Biomedical Sciences, Oregon State University, Corvallis, OR 97331,

\section{*Corresponding authors: \\ Dr. Abdur Rub \\ Email I.D. arub@jmi.ac.in}

\begin{abstract}
:
Acacia nilotica is an important medicinal plant, found in Africa, the Middle East, and the Indian subcontinent. Every part of the plant possesses a wide array of biologically-active and therapeutically important compounds and has been used in the traditional system of medicine. We reported the antileishmanial activity of Acacia nilotica (A. nilotica) bark methanolic extract through in vitro assays and dissected the mechanism of its action through in silico studies. Bark methanolic extract exhibited anti-promastigote and anti-amastigote potency with $\mathrm{IC}_{50}$ value of $19.6 \pm 0.9037 \mu \mathrm{g} / \mathrm{ml}$ and $77.52 \pm 5.167 \mu \mathrm{g} / \mathrm{ml}$ respectively in time and dose-dependent manner.
\end{abstract}


It showed very low cytotoxicity having a $\mathrm{CC}_{50}$ value of $432.7 \pm 7.71 \mu \mathrm{g} / \mathrm{ml}$ on the humanmacrophage cell line, THP-1. The major constituents identified by GC-MS analysis are 13docosenoic acid (34.06\%), lupeol (20.15\%), 9,12-octadecadienoic acid (9.92\%), and 6octadecanoic acid $(8.43 \%)$ bind effectively with the potential drug-targets of Leishmania donovani (L. donovani) including sterol 24-c-methyltransferase (SMT), trypanothione reductase (TR), pteridine reductase (PTR1) and adenine phosphoribosyltransferase (APRT); suggest the possible mechanism of its antileishmanial action. The highest affinity with all these targets was shown by lupeol. The pharmacokinetic studies, predicted bioactivity scores, and acute toxicity studies of major extract constituents support safe antileishmanial drug candidates. This study proved the antileishmanial potential of bark-methanolic extract A. nilotica and its mechanism of action through the inhibition of potential drug targets of L. donovani.

Keywords: Leishmania; Acacia nilotica; antileishmanial, drugs; host; infection; in silico

Running Title: Antileishmanial potential of A. nilotica bark extract

\section{Introduction:}

Visceral leishmaniasis (VL), also known as Kala-Azar in the Indian subcontinent, is a fatal form of the vector-borne disease caused by protozoan parasites L. donovani. The disease remains endemic in more than 60 countries around the globe, while $95 \%$ of cases are concentrated in 7 to 8 countries. More than $50 \%$ of the global burden of VL is found in the Indian subcontinent (India, Bangladesh, and Nepal). ${ }^{1,2}$ The disease is proved to be fatal if left untreated in more than $95 \%$ of cases because of secondary infection and anemia. ${ }^{3}$ VL is ranked second in mortality rate among the neglected tropical diseases. ${ }^{4,5}$ It is a significant problem for the economically weaker section of the society. Due to their unhygienic living environment, they are more vulnerable to the disease. Illiteracy is another factor that is directly proportional to the lack of awareness which 
leads to major morbidity and mortality. The available chemotherapy of visceral leishmaniasis is limited and undermined by drug resistance. Currently, in general, the drug used in the Indian subcontinent sodium antimony gluconate (SAG) showed no response in more than $64 \%$ of the patients due to the development of resistance against the parasites. ${ }^{6}$ Alternate drugs, miltefosine, amphotericin B, and its lipid formulations have several limitations because of high toxicity, cost, and unavailability, limit its use. The present scenario of disease and its limited treatment options demand an urgent need to develop a promising and cost-effective operational drug to overcome the disease. In the case of parasitic disease, directly targeting parasites is found to be significant in disease recovery. To date, large numbers of medicinal plants and their extracts had been studied for antileishmanial activity and proved to be potential therapeuticoptions. ${ }^{7,8}$ Here, we planned to explore the antileishmanial activity of the medicinal plant, A. nilotica. A. nilotica is commonly known as babul, belongs to the family Fabaceae of genus Acacia, is an important medicinal plant, found in Africa, the Middle East, and the Indian subcontinent. ${ }^{9-11}$ It is rich in secondary metabolites including condensed tannins, flavonoids, gums and phlobatannins. ${ }^{12,} 13$ Every part of the plant possess a wide array of biologically active, therapeutically potential compounds that have been used in traditional system of medicine, as a remedy for various diseases. Its different parts are used in the treatment of different diseases like floral parts for gastrointestinal disorders ${ }^{14}$, leaves extracts for cancer and microbial infections ${ }^{15}, 16$, roots extract for tuberculosis and liver disorders ${ }^{17}$ bark for bacterial infections including cold, bronchitis, dysentery, biliousness, cholera, bleeding piles. ${ }^{12,} 18-20$ The extract of bark contains the different form of tannins ((-) - epigallocatechin-7-gallat, (-) - epigallocatechin-5,7-digallat, dicatechin $)^{21,22}$, flavonoids ( (+)-catechin-5-gallate, (+)-catechin-5,7-digallate, (+)-catechin-3',5digallate, $\quad(+)$-catechin-4',5-digallate, $\quad(+)$-mollisacacidin, $\quad$ apigenin-6,8-bis-C- $\beta$-D- 
glucopyranoside (vicenin), leucocyanadin, kaempferol-7-glucoside, acacetin, umbelliferon, caffeic acid, protocatechuic acid and m-catechol. ${ }^{12,23,24}$ Keeping the rich antimicrobial bioactive collection of bark of A. nilotica, in mind, we planned to study its antileishmanial potential here. We also tried to dissect the mechanism of its antileishmanial action through different in silico approaches. SMT, TR, PTR1, and APRT are prerequisite enzymes for survival, pathogenicity, and transmission of $L$. donovani. Therefore, we selected these potential drug-targets for molecular docking study of major constituents of bark-extract identified by GC-MS, with these mentioned essential enzymes of Leishmania.

\section{Materials and method}

2.1 Chemicals: M199 media, Roswell park memorial institute (RPMI) 1640 media, penicillinstreptomycin antibiotic cocktail, fetal bovine serum (FBS) were purchased from Gibco. HEPES, sodium bicarbonate, and paraformaldehyde were purchased from Sigma Aldrich. Miltefosine, MTT assay reagents, DMSO, and different solvents were procured from Merck. Propidium iodide and Annexin $\mathrm{V}$ apoptosis kit were procured from Thermo scientific. All the other chemicals and reagents were purchased from Sigma Aldrich or Merck unless stated otherwise.

\subsection{Parasites and cell culture:}

The infective strain of $L$. donovani (MHOM/IN/83/AG83) was obtained from Dr. Rentala Madhubala (School of life science JNU, New Delhi; India). THP-1, a human monocytic cell line was procured from the Cell Repository of National Centre for Cell Science, Pune, India. It was further maintained in M199 media. Human monocytic cell line, THP-1 was maintained in RPMI 1640 media supplemented with $10 \%$ FBS and $1 \%$ penicillin-streptomycin antibiotic medium in a humidified environment at $5 \% \mathrm{CO}_{2}$ and $37^{\circ} \mathrm{C}$ temperature. THP- 1 monocytic cell was 
differentiated to macrophages by using phorbol myristate acetate (PMA) at a concentration of 20 $\mathrm{ng} / \mathrm{ml}$.

\subsection{Extract preparation and antileishmanial activity:}

A. nilotica was collected from natural habitats. Bark identification was done at the National Institute of Science Communication and Information Resources (NISCAIR), New Delhi, India. The selected plant material was washed and air-dried in shade at room temperature. The powdered plant materials were soaked in methanol and placed on the rotary shaker at room temperature for $24 \mathrm{~h}$. The extract was filtered and concentrated using a rotatory evaporator under vaccum at $35^{\circ} \mathrm{C}$. The dried plant extract was stored at $-20^{\circ} \mathrm{C}$ until used for bioassay. To evaluate the anti-promastigote potential of $A$ nilotica, stationary phase $\left(2 \times 10^{6}\right.$ cells $\left./ \mathrm{ml}\right)$ promastigotes were incubated with plant extract for $48 \mathrm{~h}$ followed by fixing using $1 \%$ paraformaldehyde and counting through hemocytometer at $22^{\circ} \mathrm{C}$. Miltefosine a known antileishmanial drug used as positive control. Percent viability was determined using the formula:

$$
\% \text { Viability }=\frac{\text { Average parasite count per } m l(\text { treated })}{\text { Average parasite count per } m l(\text { control })} \times 100
$$

$50 \%$ inhibitory concentration $\left(\mathrm{IC}_{50}\right)$ at which parasite growth was reduced by $50 \%$ was assessed by GraphPad Prism 7.00, nonlinear regression curve fit.

\subsection{Cytotoxicity assessment and anti-amastigote evaluation of extract:}

The cytotoxicity of A. nilotica on THP-1 differentiated macrophages was assessed by MTT [3(4,5 dimethyl- thiazol-2-yl)-2,5-diphenyl tetrazolium bromide]. Briefly, $2 \times 10^{6}$ THP-1 monocytes were seeded in 96 well tissue culture plate $(200 \mu \mathrm{l} /$ well $)$ in RPMI1640 complete media for $24 \mathrm{~h}$ in a $\mathrm{CO}_{2}$ incubator at $37^{0} \mathrm{C}$ and $5 \% \mathrm{CO}_{2}$. After treatment to THP-1 differentiated macrophages, freshly prepared $5 \mathrm{mg} / \mathrm{ml}$ MTT was added $(20 \mu \mathrm{l} /$ well $)$ with $50 \mu \mathrm{l}$ of blank media 
and further incubated for 2 to $3 \mathrm{~h}$ in a $\mathrm{CO}_{2}$ incubator. Precipitated formazan was dissolved in dimethyl sulfoxide (DMSO) absorbance was recorded at $570 \mathrm{~nm}$ in an ELISA plate reader and percent viability was calculated. To determine the effect of A. nilotica on the parasite burden of the host macrophages, $0.5 \times 10^{6}$ THP- 1 cells were seeded on the coverslip, placed in the six-well plates in a $\mathrm{CO}_{2}$ incubator at $37^{\circ} \mathrm{C}$. THP-1 macrophages were plated, infected with $L$. donovani at the ratio of 1:10 (macrophages to Leishmania) for $48 \mathrm{~h}$ then cells were fixed with chilled methanol and parasite counting was performed under the microscope after Giemsa staining. From the different focus, 100 macrophages were counted to determine the parasite burden of the macrophages. Parasite burden in the infection control was considered $100 \%$, with respect to parasite load in treated samples.

\subsection{GC-MS analysis of extract:}

GC-MS analysis was performed to identify the secondary metabolites that may be responsible for the antileishmanial efficacy of $A$ nilotica. Bark was crushed, powdered, and extracted in methanol and then analyzed on Shimadzu QP2010 armed with a DB-5MS column. The mass spectrums of the sample were produced in an electron impact ionization mode of $70 \mathrm{eV}$ and the phytochemicals were identified after correlation of the recorded mass spectrum with the reference library WILEY8.LIB and NIST14.LIB supplied with the software of the GC-MS system.

\subsection{Molecular docking studies:}

To begin with structure-based virtual screening and docking, we used various bioinformatics tools, such as PyRx ${ }^{25}$, AutoDock Vina ${ }^{26}$, PyMOL ${ }^{27}$, and BIOVIA Discovery Studio. ${ }^{28}$ The online resources used in the retrieval, analysis, and evaluation of the data are the PubChem database and RCSB Protein Data Bank (PDB) ${ }^{29}$ The target proteins of $L$. donovani and the 
phytochemical compounds were uploaded into the virtual screening program PyRx. The target protein was changed into a macromolecule, which converted the atomic coordinates into pdbqt format. Molecular docking was performed by selecting the grid box around the crystal structures and the rest of the parameters were left as default. AutoDock Vina was used to predicting the binding mode and the best binding affinity of the phytochemicals. The algorithm used by AutoDock Vina is a hybrid scoring function that is inspired by $\mathrm{X}$-score, which accounts for hydrogen bonding, hydrophobic effect, van der Waals forces, and deformation penalty. Besides, for computing, the binding energy AutoDock Vina combines both the conformational preferences of receptor-ligand complex and experimental affinity measurements. The results of molecular docking were screened for binding affinity and then all possible docked conformations were generated for different constituents. After analyzing with PyMOL and Discovery Studio, only those conformations were selected which specifically interact with the active-site residues of L. donovani targeted proteins. Discovery Studio was used to analyze detailed interactions and their types including hydrogen bonds, alkyl, pi-alkyl, halogen, and the van der Waals interactions formed between different constituents and the target proteins. The most favorable binding poses of the rutin were analyzed by choosing the lowest free energy of binding $(\Delta G)$ and the lowest inhibition constant $(\mathrm{Ki})$ which is calculated using the following formula:

\section{$K \mathrm{i}_{\text {pred }}=$ exponential $^{(\Delta \mathrm{G} / \mathrm{RT})}$}

where $\Delta \mathrm{G}$ is binding affinity $(\mathrm{kcal} / \mathrm{mol}), \mathrm{R}$ (gas constant) is $1.98 \mathrm{calK}^{-1} \mathrm{~mol}^{-1}$, and $\mathrm{T}$ (room temperature) is 298.15 Kelvin. 


\subsection{Sequence analysis, template identification, homology modeling, and receptor and ligand preparation}

The protein sequences of trypanothione reductase (XP_003858222.1) and sterol 24-cmethyltransferase (XP_003865366.1) from $L$. donovani were retrieved from NCBI. The blastP ${ }^{30}$ was performed against Protein Data Bank for the identification of similar templates. The alignment of the query sequences and template sequences was performed using CLUSTAL $\Omega .{ }^{31}$ The crystal structure of trypanothione reductase from L. infantum $2.95 \AA$ resolution (PDB id: 2JK6_A) and X-ray diffracted crystal structure 1.34 Å resolution (PDB id: 5WP4_A) were used as template structures to model the 3D structures of trypanothione reductase and sterol 24-cmethyltransferase, respectively. PDB was used to retrieve the template structure. Homology modelling was carried out using Modeller $9.24{ }^{32}$ and PyMol was used for the visualization of the 3D structures. The energy minimization was performed using Discovery studio. The PROCHECK program, Ramachandran plots were also used for the assessment of the model. ${ }^{33}$ Crystal structures of the Adenine phosphoribosyltransferase and Pteridine reductase proteins were downloaded from PDB [IDs: 1QB7 (APRT) and 2XOX (PTR1)]. The PDB files used for the docking-based virtual screening study were processed by removing water molecules and adding hydrogen atoms. The proteins were finally prepared by Discovery Studio keeping all the parameters at default. The identification of the critical residues of the binding pockets was taken from the native binding pockets of the available crystal structure of proteins, various submitted literature, from their homologous template proteins, and investigation in the mechanism of inhibition. The 3D structure of 9,12-Octadecadienoic acid, 6-Octadecenoic acid, 13-Docosenoic acid, and Lupeol was retrieved from the PubChem database in SDF format. The atomic coordinates of all the ligands were changed to pdbqt set-up using Open Babel GUI, an open- 
source chemical toolbox for the interconversion of chemical structures. ${ }^{34}$ Universal Force Field (uff) was used for the energy minimization. ${ }^{35}$

\subsection{Pharmacokinetics studies}

The selected ligands were evaluated for their pharmacological profiles by analyzing for Lipinski's rule of violation-5, which was analyzed by Molsoft L.L.C.: Drug-Likeness and molecular property prediction for drug-likeness. (http://www.molsoft.com/mprop/) The bioactivity of the selected inhibitors was checked by Molinspiration. (https://molinspiration.com/cgi-bin/properties). The successfully screened ligands were further evaluated for ADMET (absorption, distribution, metabolism, excretion, and toxicity) properties by GUSAR ${ }^{36}$ and SwissADME database. ${ }^{37}$

\section{Results:}

\section{1 Antileishmanial activity of $A$. nilotica on $L$. donovani promastigotes:}

The growth inhibitory effects of $A$. nilotica bark methanolic extract fraction was assessed against exponentially growing $L$. donovani promastigotes. A. nilotica treatment reduced the promastigotes proliferation in a time and dose-dependent manner. Growth kinetics was assessed for seven days; there was a gradual decrease in the promastigote proliferation at all the doses (Figure 1A). The promastigote culture was completely shattered at the dose concentration of 250 and $500 \mu \mathrm{g} / \mathrm{ml}$ of $A$. nilotica, after the three days of treatment. Miltefosine, an established antileishmanial drug rapidly shattered the promastigote parasites in vitro. The Leishmania promastigotes without any treatment or with $0.5 \%$ DMSO (solvent control), exponentially grow till the $4^{\text {th }}$ day of parasites seeding, conforming to no antileishmanial potential of solvent. After $4^{\text {th }}$ day of the experimental setup, the culture even in the control and the solvent control was gradually decreased, because of media exhaustion. The $\mathrm{IC}_{50}$ value of A. nilotica on Leishmania- 
promastigotes was calculated as $19.6 \pm 0.9037 \mu \mathrm{g} / \mathrm{ml}$ and the miltefosine treated positive control has the $\mathrm{IC}_{50}$ of $3.118 \pm 0.2395$ (Figure 1B). A. nilotica treatment exhibits the morphological changes in the promastigote stage parasites, though at lower doses the parasites retained normal morphology. At the higher concentrations, there is a reduction in size and shortening of flagella. Miltefosine treatment also exhibited similar morphological changes as extract showed at higher doses (Figure 1C).

\subsection{Growth reversibility assay after extract treatment:}

A. nilotica, treated and untreated parasites were washed with PBS after 7 days, and old media was removed and supplemented with fresh media. The samples were further incubated at $22{ }^{\circ} \mathrm{C}$ for the next $72 \mathrm{~h}$ to study the growth reversibility of parasites. Parasites treated with higher doses do not revert though parasites in flasks of lower dose plant-extract treatment show slower growth reversion (Figure 1D). Suppression of growth reversion was observed significant $(P<0.001)$ at $250 \mu \mathrm{g} / \mathrm{ml}$ of A. nilotica in comparison to the untreated sample (Figure 1D).

\subsection{Cytotoxicity and antileishmanial activity of $A$. nilotica on intra-macrophagic} amastigotes

Upon internalization, promastigotes are transformed into the amastigote form inside the parasitophorous vacuoles of macrophages. These amastigote forms of the parasites are nonmotile and define the parasite pathogenicity. Thus, being the biologically and clinically relevant form it was important to check the anti-amastigote efficacy of A. nilotica methanolic extract. THP-1 differentiated macrophages were parasitized by $L$. donovani promastigotes and treated with different doses of the extract. Plant extract treatment reduced the intra-macrophagic parasites in a dose-dependent manner with an $\mathrm{IC}_{50}$ value of $77.52 \pm 5.167 \mu \mathrm{g} / \mathrm{ml}$ (Figure $2 \mathrm{~A}$ ). Miltefosine was taken as a positive control (Figure 2A). Cell cytotoxicity $\left(\mathrm{CC}_{50}\right)$ of A. nilotica 
methanolic extract was evaluated along with miltefosine as a positive control on THP-1 differentiated macrophages to study its safe dose. THP-1 differentiated macrophages were incubated with different concentrations of extract/miltefosine ( 0 to $1000 \mu \mathrm{g} / \mathrm{ml})$ and the cell viability was assessed using MTT assay. It was observed that A. nilotica has the least cytotoxic effect on the viability and morphology of the macrophages with a $\mathrm{CC}_{50}$ value of $432.7 \pm 7.71$ $\mu \mathrm{g} / \mathrm{ml}$ while miltefosine showed higher toxicity with a $\mathrm{CC}_{50}$ value of $8.219 \pm 0.6337 \mu \mathrm{g} / \mathrm{ml}$ (Figure 2B). A significant reduction in intra-macrophagic parasite count was observed in the micrographs of Giemsa stained infected and extract treated macrophages (Figure 2C).

\subsection{TLC-bioautography identification and GC-MS analysis of $A$. nilotica bark methanolic} extract:

Plant secondary metabolites present in A. nilotica bark methanolic extract fractions that may have been responsible for the observed antileishmanial effects were identified through TLCbioautography and GC-MS analysis. The total constituents found were 25 (Table 1) out of which the major constituents were 13-docosenoic acid (34.06 \%), lupeol (20.15\%), 9,12octadecadienoic acid (9.92\%), and 6-octadecanoic acid (8.43\%).

3.5 Molecular docking of A. nilotica methanolic extract of major constituents with potential drug-targets of L. donovani

The TR and SMT enzymes were modelled using Modeller 9.24 and the energy minimization was carried out by BIOVIA Discovery studio. The three-dimensional cartoon representation of TR and SMT enzymes is shown in Figure S1A,2A. The models were selected by analyzing their stereochemical quality using the PROCHECK program. The generated models of TR and SMT show a good quality structure having $99.8 \%$ and $99 \%$ residues in the allowed regions of the Ramachandran plot respectively (Figure S1B,2B). PDBsum tool was used to analyze and found 
that the 3D structure of the enzyme is composed of mixed $\alpha$-helices and $\beta$-strands $(\alpha+\beta)$ secondary structures. ${ }^{33}$ The structural topology of TR and SMT showed 5 sheets, 23 strands, 18 helices and 34 beta turns and 2 sheets, 10 strands, 14 helices, and 41 beta turns, respectively (Figure S1C-D, S2C-D). Multiple sequence alignments were performed and Discovery studio was used to find the key residues and regions around the binding cavity of TR and SMT. The active site residues of the SMT, TR, PTR1, and APT enzymes making different numbers of hydrogen bonds as well as hydrophobic bonds with the ligands were also identified. Based on binding affinity Lupeol; 9,12-Octadecadienoic acid; 6-Octadecenoic acid; and 13-Docosenoic acid have binding energies of $-8.5 \mathrm{kcal} / \mathrm{mol},-5.7 \mathrm{kcal} / \mathrm{mol},-5.7 \mathrm{kcal} / \mathrm{mol}$, and $-5.6 \mathrm{kcal} / \mathrm{mol}$; $-8.4 \mathrm{kcal} / \mathrm{mol},-4.9 \mathrm{kcal} / \mathrm{mol},-4.9 \mathrm{kcal} / \mathrm{mol}$, and $-4.7 \mathrm{kcal} / \mathrm{mol} ;-7.9 \mathrm{kcal} / \mathrm{mol},-5.3 \mathrm{kcal} / \mathrm{mol}$, $-4.4 \mathrm{kcal} / \mathrm{mol}$, and $-5.4 \mathrm{kcal} / \mathrm{mol} ;-6.2 \mathrm{kcal} / \mathrm{mol},-6.1 \mathrm{kcal} / \mathrm{mol},-5.9 \mathrm{kcal} / \mathrm{mol}$, and $-5.9 \mathrm{kcal} / \mathrm{mol}$ with SMT, TR, PTR1, and APT enzymes, respectively (Table 2). The binding pattern of lupeol with SMT, TR, PTR1, and APT may hinder the substrate accessibility and its subsequent inhibition as shown in (Figure 3-6A) where the binding energies and inhibition constants are $-8.5 \mathrm{kcal} / \mathrm{mol},-8.4 \mathrm{kcal} / \mathrm{mol},-7.9 \mathrm{kcal} / \mathrm{mol},-6.2 \mathrm{kcal} / \mathrm{mol}$, and $6.25 \mu \mathrm{M}, 6.12 \mu \mathrm{M}, 5.81 \mu \mathrm{M}$, $4.56 \mu \mathrm{M}$ respectively (Table 2). It shows favorable interactions with SMT through two pi-alkyl bonds with Arg347 and Lys351, TR via a pi-alkyl bond with Tyr198, PTR1 by two pi-alkyl bonds with Val83 and Arg88, and APRT through a hydrogen bond with Thr151. (Figure 3-6B). The binding interaction shown by 9,12-Octadecadienoic acid with SMT, TR, PTR1 and APRT, may obstruct the substrate accessibility of these proteins which leads to their subsequent inhibition as shown in (Figure 3-6C) where the binding energies and inhibition constants are $-5.7 \mathrm{kcal} / \mathrm{mol},-4.9 \mathrm{kcal} / \mathrm{mol},-5.3 \mathrm{kcal} / \mathrm{mol},-6.1 \mathrm{kcal} / \mathrm{mol}$, and $4.19 \mu \mathrm{M}, 3.60 \mu \mathrm{M}, 3.90 \mu \mathrm{M}$, 4.49 $\mu \mathrm{M}$, respectively (Table 2). The favorable interactions are shown by 9,12-Octadecadienoic 
acid with SMT through a hydrogen bond with Lys198, TR via a hydrogen bond with Gly376, PTR1 by eighteen pi-alkyl bonds with Phe86, Lys87, Ala90, Ala94, Lys156, Ala157, His160, Arg161, and APRT through a hydrogen bond with Arg82. (Figure 3-6D). The binding pattern of 6-Octadecenoic acid with SMT, TR, PTR1, and APRT may lead to their subsequent inhibition by obstructing their substrate accessibility as shown in (Figure 3-6E) where the binding energies and inhibition constants are $-5.7 \mathrm{kcal} / \mathrm{mol},-4.9 \mathrm{kcal} / \mathrm{mol},-4.4 \mathrm{kcal} / \mathrm{mol},-5.9 \mathrm{kcal} / \mathrm{mol}$, and 4.19 $\mu \mathrm{M}, 3.60 \mu \mathrm{M}, 3.24 \mu \mathrm{M}, 4.34 \mu \mathrm{M}$, respectively (Table 2). The important and favorable interactions shown by 6-Octadecenoic acid with SMT through two pi-alkyl bonds with Lys198, TR via a hydrogen bond with Gly376, PTR1 by a hydrogen bond with Leu92, and APRT through two hydrogen bonds with Arg37 and Arg82. (Figure 3-6F).

The pattern of interaction of 13-Octadecenoic acid with SMT, TR, PTR1, and APRT may lead to their subsequent inhibition by obstructing their substrate accessibility as shown in (Figure 3-6G) where the binding energies and inhibition constants are $-5.6 \mathrm{kcal} / \mathrm{mol},-4.7 \mathrm{kcal} / \mathrm{mol},-5.4$ $\mathrm{kcal} / \mathrm{mol},-5.9 \mathrm{kcal} / \mathrm{mol}$, and $4.12 \mu \mathrm{M}, 3.46 \mu \mathrm{M}, 3.97 \mu \mathrm{M}, 4.34 \mu \mathrm{M}$ respectively (Table 2). It shows favorable interactions with SMT through two hydrogen bonds with Lys241 and Gln263, TR via a hydrogen bond with Gly376, PTR1 by twenty pi-alkyl bonds with Val83, Phe86, Lys87, Ala90, Ala94, Lys156, Ala157, His160, and APRT through a hydrogen bond with Arg37 and Ar82. (Figure 3-6H).

\subsection{Pharmacokinetics studies of $\boldsymbol{A}$. nilotica bark-methanolic extract constituents:}

The pharmacological studies were done for the selected ligands against Adenine phosphoribosyltransferase, Pteridine reductase, trypanothione reductase, and sterol 24-cmethyltransferase proteins for a good oral administration established through the Lipinski rule of five $^{38}$, which was evaluated by Molsoft L.L.C.: Drug-Likeness and molecular property 
prediction. Lipinski's "rule of five" is an analytical approach for predicting drug-likeness stating that molecules had Molecular weight (M.W. $\leq 500$ Da), high lipophilicity expressed as LogP $(\operatorname{LogP} \leq 5)$, hydrogen bond donors $(\mathrm{HBD} \leq 5)$, and hydrogen bond acceptors $(\mathrm{HBA} \leq 10)$ have good absorption or permeation across the cell membrane. Lupeol, 9,12-Octadecadienoic acid, 6Octadecenoic acid, and 13-Docosenoic acid followed all the parameters of the Lipinski rule of five, except low lipophilicity as observed from Table 2. As per the Lipinski rule of five, violation of one parameter is acceptable for an orally active drug. The absorption percentage ( $\mathrm{AB} \%)$ was calculated using the formula. ${ }^{39}$

$\mathrm{AB} \%=[109-(0.345 \times \mathrm{TPSA})]$

It is important to look into the pharmacokinetic properties of the compounds, before animal and clinical studies. To evaluate the biochemical behavior of these compounds inside an organism in respect of absorption, distribution, metabolism, and excretion (ADME), SwissADME database ${ }^{37}$ was used to explore the drug-likeness and pharmacokinetics properties of these compounds. The lipophilicity of Lupeol, 9,12-Octadecadienoic acid, 6-Octadecenoic acid, and 13-Docosenoic acid showed LogPo/w value of 4.76, 4.61, 4.73, and 5.65 that indicates high sublingual absorption respectively. Lupeol and 13-Docosenoic acid possess low gastrointestinal absorption and poor water-soluble capability whereas 9,12-Octadecadienoic acid and 6-Octadecenoic acid shows high gastrointestinal absorption as well as moderate water-soluble capability. None of the compounds are permeable to the blood-brain barrier. 9,12-Octadecadienoic acid, 6-Octadecenoic acid, and 13-Docosenoic acid are CYP1A2 inhibitors, which likely to increase the half-life of these compounds and also prevent serious drug interactions. The drug-likeness criteria are qualified by all the ligands with one violation and possess a significant bioavailability score. The results are summarized in Table 3. 
The bioactivity prediction of the major constituents of A. nilotica bark-methanolic extract was analyzed through molinspiration. The activity was calculated against G-protein coupled receptorligand, ion channel modulator, a kinase inhibitor, nuclear receptor ligand, protease inhibitor, and enzyme inhibitor. ${ }^{40}$ The interpreted values for bioactivity were as: active (bioactivity score $\geq 0$ ), moderately active (bioactivity score: between -5.0 to 0.0 ), and inactive (bioactivity score $\leq-5.0) .{ }^{41}$ Lupeol, 9,12-Octadecadienoic acid, 6-Octadecenoic acid, and 13-Docosenoic acid were evaluated as active enzyme inhibitors with values $0.52,0.23,0.12$, and 0.10 , respectively. Lupeol and 9,12-Octadecadienoic acid were evaluated as active protease inhibitors as well as ion channel modulators. (Table 4)

The principal aim of predicting acute toxicity is to evaluate undesirable side effects of a compound after single or multiple exposures to an organism via a known administration route (oral, inhalation, subcutaneous, intravenous, or intraperitoneal). GUSAR was used to determine the acute toxicity of the successfully docked compounds. The parameters used by GUSAR to probe compounds based on the prediction of activity spectra for substances algorithm and quantitative neighborhoods of atoms descriptors. The obtained results were compared with SYMYX MDL Toxicity Database to further categorize them based on the Organisation for Economic Co-operation and Development (OECD) chemical classification manual. ${ }^{36}$ The criteria used for these compounds to elicit toxicity based upon the administration route when the compound dose is more than $7000 \mathrm{mg} / \mathrm{kg}$ for an intravenous route, more than $500,000 \mathrm{mg} / \mathrm{kg}$ in case of the oral route, and more than $20,000 \mathrm{mg} / \mathrm{kg}$ for intraperitoneal route and subcutaneous database as shown in Table 5. As per the OECD chemical classification 9,12- Octadecadienoic acid, 6-Octadecenoic acid, 13-Docosenoic acid found to be non-toxic and Lupeol is a Class 5 chemical. 


\section{Discussion:}

Plant extracts have promising medicinal properties and are extensively used in the traditional system of medicine due to the presence of many active and leading medicinal. ${ }^{42}$ From the previous studies, it has been revealed that many medicinal plants-extracts and their secondary metabolite contents have proven to be efficient and low toxic antileishmanial drug candidates. ${ }^{43}$,

${ }^{44}$ A. nilotica which has been identified as potential medicinal plants, are rich in secondary metabolites. Studies based on GC-MS analysis of A. nilotica showed the presence of different types of secondary plant metabolites including polyphenols, mainly composed of condensed tannin and phlobatannin in addition to gallic acid, ellagic acid, catechin, epigallocatechin-7gallate, flavonoids, and gum. ${ }^{13}$ Different solvent extracts of the A. nilotica had been shown to have antimicrobial activities including anti-bacterial, anti-fungal, anti-viral, and anti-amebic. ${ }^{18,45}$, 46 We evaluated the antileishmanial potential of A. nilotica and identified its secondary metabolite constituents by GC-MS analysis. A. nilotica bark methanolic extract repressed the growth of $L$. donovani promastigotes in a time and dose-dependent manner. It induced morphological changes and cytocidal mode of parasite killing. The cytocidal mode of the killing of A. nilotica maybe because of its richness in phenolic compounds ${ }^{47}$ and phenolic acids which cause irreversible changes to the cell membrane ${ }^{48}$ Methanolic extract of the fruit of A. nilotica has been reported to have antileishmanial activity with an $\mathrm{IC}_{50}$ value of $89.38 \mu \mathrm{g} / \mathrm{ml}$ on the $L$. major promastigotes. ${ }^{49}$ Here, we for the first time studied the role of A. nilotica bark-methanolic extract against the growth and proliferation of $L$. donovani promastigotes and intra-macrophagic amastigotes. The $\mathrm{IC}_{50}$ value of A. nilotica was determined as $19.6 \pm 0.9037 \mu \mathrm{g} / \mathrm{ml}$, which is higher as compared to the $\mathrm{IC}_{50}$ value of positive control miltefosine as $3.118 \pm 0.2395 \mu \mathrm{g} / \mathrm{ml}$. But the $\mathrm{CC}_{50}$ value of A. nilotica on macrophages was $432.7 \pm 7.71 \mu \mathrm{g} / \mathrm{ml}$, while that of the 
miltefosine was $8.219 \pm 0.6337 \mu \mathrm{g} / \mathrm{ml}$. The plant extract significantly inhibited the growth of the intra-macrophagic form of the parasites. The $\mathrm{IC}_{50}$ value of the extract on amastigote form was calculated as $77.52 \pm 5.167 \mu \mathrm{g} / \mathrm{ml}$. A. nilotica has found to have low cytotoxic even after having a higher $\mathrm{IC}_{50}$ value as compare to the miltefosine. So, the higher concentration of $A$. nilotica can be used to inhibit the growth of amastigotes inside macrophages. The major constituents identified through GC-MS analysis were 13-docosenoic acid (34.06\%), lupeol (20.15\%), 9,12octadecadienoic acid $(9.92 \%)$ and 6-octadecanoic acid $(8.43 \%)$. To dissect the mechanism of antileishmanial activity of A. nilotica, we further performed the molecular docking study of major constituents of extract identified by GC-MS, with essential enzymes of Leishmania including SMT, TR, PTR1, and APRT. These enzymes play an essential role in parasite growth, survival, virulence, and transmission inside the host. SMT is required for the biosynthesis of ergosterol, the major membrane sterol in L. donovani ${ }^{50}$. The enzyme TR follows thiol-redox metabolism to keep trypanothione in reduced form. This antioxidant property of TR is essential for the survival of L. donovani. ${ }^{51}$ PTR1 catalyzes the reduction of conjugated and nonconjugated pterins such as reduced biopterin to dihydrobiopterin. ${ }^{52}$ APRT plays a vital role in purine metabolism by converting 6-aminopurines into 6-oxypurines. ${ }^{53}$ Molecular docking results prove that lupeol and 9,12-Octadecadienoic acid possesses higher binding affinity with SMT, TR, PTR1, and APRT as shown in Table 2. Pharmacological studies of these selected inhibitors for the Lipinski rule of 5 indicated violation of only one Lipinski parameter, as shown in Table 3. The pharmacokinetic properties and acute toxicity of lupeol; 9,12-Octadecadienoic acid;6Octadecenoic acid and 13-Docosenoic acid have shown relatively low toxicity profile, which means require high doses to evoke a toxic response. The majority of the compounds are nontoxic chemicals whereas lupeol is a Class 5 chemical with very low toxic effects. ${ }^{54}$ The 
pharmacokinetic attributes are in favor of these compounds to be exploited as promising antileishmanial drug candidates. It had already been reported that lupeol activates the PI3K/Akt pathway which triggers mechanisms responsible for influencing various cell types, including keratinocytes, stimulated cytotoxicity in fibroblasts, and the regulation of various diseases..$^{55}$ The lupeol treatment had shown a high imbalance between Th1/Th2 cytokines production and initiation of pro-inflammatory cytokine response as well as the generation of NO in L. donovani infected macrophages. ${ }^{56}$ It further supports the antileishmanial activity of A. nilotica extract. Thus, in vitro, molecular docking, pharmacokinetics studies, bioactivity scores, and acute toxicity studies support possible mechanisms of antileishmanial activity of the extract through inhibition of key Leishmania enzymes.

\section{Acknowledgment}

The authors would like to thank the Deanship of Scientific Research at Majmaah University, Al Majmaah, 11952, Saudi Arabia for supporting this work under the Group Project Number RGP2019-31. The authors also would like to thank the Ministry of AYUSH (Z. 28015/252/2015HPC(EMR)-AYUSH-C) GoI for supports. ST is thankful to ICMR, GoI for SRF. RA is thankful to AYUSH, GoI for SRF.

\section{Conflict of interest}

The author showed no conflict of interest.

\section{Author Contribution}

The study was conceptualized by AR, SB and AABD, ASA; data acquisition and data analysis were performed by ST, RA, and FR; manuscript preparation and manuscript editing were performed by AR, SB, AABD, FR, ASA, BMA, FAA, MAA and ST; the final manuscript was checked by AR and AABD; the fund was obtained by SB, ASA, FAA, MAA, AABD and AR 


\section{References:}

1. Murray, H. W.; Berman, J. D.; Davies, C. R.; Saravia, N. G., Advances in leishmaniasis. Lancet 2005, 366 (9496), 1561-77.

2. $\quad$ Huda, M. M.; Hirve, S.; Siddiqui, N. A.; Malaviya, P.; Banjara, M. R.; Das, P.; Kansal, S.; Gurung, C. K.; Naznin, E.; Rijal, S., Active case detection in national visceral leishmaniasis elimination programs in Bangladesh, India, and Nepal: feasibility, performance and costs. BMC public health 2012, 12 (1), 1001.

3. $\quad$ Piscopo, T. V.; Mallia Azzopardi, C., Leishmaniasis. Postgraduate medical journal 2007, 83 (976), 649-57.

4. Global, regional, and national disability-adjusted life-years (DALYs) for 315 diseases and injuries and healthy life expectancy (HALE), 1990-2015: a systematic analysis for the Global Burden of Disease Study 2015. Lancet 2016, 388 (10053), 1603-1658.

5. Wang, H.; Naghavi, M.; Allen, C.; Barber, R. M.; Bhutta, Z. A.; Carter, A.; Casey, D. C.; Charlson, F. J.; Chen, A. Z.; Coates, M. M., Global, regional, and national life expectancy, all-cause mortality, and cause-specific mortality for 249 causes of death, 1980-2015: a systematic analysis for the Global Burden of Disease Study 2015. The lancet 2016, 388 (10053), 1459-1544.

6. Sundar, S., Drug resistance in Indian visceral leishmaniasis. Tropical medicine \& international health : TM \& IH 2001, 6 (11), 849-54.

7. Chouhan, G.; Islamuddin, M.; Want, M. Y.; Abdin, M. Z.; Ozbak, H. A.; Hemeg, H. A.; Sahal, D.; Afrin, F., Apoptosis mediated leishmanicidal activity of Azadirachta indica bioactive fractions is accompanied by Th1 immunostimulatory potential and therapeutic cure in vivo. Parasites \& vectors 2015, 8, 183.

8. Islamuddin, M.; Chouhan, G.; Tyagi, M.; Abdin, M. Z.; Sahal, D.; Afrin, F., Leishmanicidal activities of Artemisia annua leaf essential oil against Visceral Leishmaniasis.

Frontiers in microbiology 2014, 5, 626.

9. Hill, A. F., Some nomenclatorial problems in Acacia. Botanical Museum leaflets, Harvard University 1940, 8 (5), 93-105.

10. Bargali, K.; Bargali, S., Acacia nilotica: a multipurpose leguminous plant. Nature and Science

2009, 7 (4), 11-19.

11. Leela, V.; Kokila, L.; Lavanya, R.; Saraswathy, A.; Brindha, P., Determination of gallic acid in Acacia nilotica Linn. by HPTLC. International Journal of Pharmacy

Technology International Journal of Pharmacy

Technology 2010, 2 (2), 285-292.

12. Singh, B. N.; Singh, B. R.; Singh, R. L.; Prakash, D.; Sarma, B. K.; Singh, H. B., Antioxidant and anti-quorum sensing activities of green pod of Acacia nilotica L. Food and chemical toxicology : an international journal published for the British Industrial Biological Research Association 2009, 47 (4), 778-86.

13. Seigler, D. S. J. B. s.; ecology, Phytochemistry of Acacia—sensu lato. 2003, 31 (8), 845873. 
14. Gilani, S. A.; Khan, A. M.; AleemQureshi, R.; Sherwani, S. K., Ethno-medicinal treatment of common gastrointestinal disorders by indigenous people in Pakistan. Advances in Bioresearch 2014, 5 (1), 42-49.

15. Al-Fatimi, M.; Wurster, M.; Schröder, G.; Lindequist, U., Antioxidant, antimicrobial and cytotoxic activities of selected medicinal plants from Yemen. Journal of ethnopharmacology 2007, 111 (3), 657-66.

16. Kalaivani, T.; Mathew, L., Free radical scavenging activity from leaves of Acacia nilotica (L.) Wild. ex Delile, an Indian medicinal tree. Food and chemical toxicology : an international journal published for the British Industrial Biological Research Association 2010, 48 (1), 298305.

17. Eldeen, I.; Van Staden, J., Antimycobacterial activity of some trees used in South African traditional medicine. South African Journal of Botany 2007, 73 (2), 248-251.

18. Bhargava, A.; Srivastava, A.; Kumbhare, V., Antifungal activity of polyphenolic complex of Acacia nilotica bark. Indian forester 1998, 124 (5), 292-298.

19. Qasim, M.; Abideen, Z.; Adnan, M. Y.; Ansari, R.; Gul, B.; Khan, M., Traditional ethnobotanical uses of medicinal plants from coastal areas. J coast life Med 2014, 2 (1), 22-30.

20. Baravkar, A.; Kale, R.; Patil, R.; Sawant, S. J. R. J. o. P., Pharmaceutical and biological evaluation of formulated cream of methanolic extract of Acacia nilotica leaves. Research Journal of Pharmacy and Technology

2008, 1 (4), 480-483.

21. Hussein Ayoub, S., Flavanol molluscicides from the Sudan Acacias. International Journal of Crude Drug Research 1985, 23 (2), 87-90.

22. Leela, V.; Saraswathy, A., Pharmacognostic studies on the flowers of Acacia nilotica Linn. Pharmacognosy Journal 2012, 4 (28), 35-39.

23. Singh, R.; Singh, B.; Singh, S.; Kumar, N.; Kumar, S.; Arora, S., Anti-free radical activities of kaempferol isolated from Acacia nilotica (L.) Willd. Ex. Del. Toxicology in vitro : an international journal published in association with BIBRA 2008, 22 (8), 1965-70.

24. Malan, E.; Roux, D. G., Flavonoids and tannins of Acacia species. Phytochemistry 1975, $14(8), 1835-1841$.

25. Dallakyan, S.; Olson, A. J., Small-molecule library screening by docking with PyRx. Methods in molecular biology (Clifton, N.J.) 2015, 1263, 243-50.

26. Trott, O.; Olson, A. J., AutoDock Vina: improving the speed and accuracy of docking with a new scoring function, efficient optimization, and multithreading. Journal of computational chemistry 2010, 31 (2), 455-61.

27. Kashif, M.; Hira, S. K.; Upadhyaya, A.; Gupta, U.; Singh, R.; Paladhi, A.; Khan, F. I.; Rub, A.; Manna, P. P. J. I. j. o. a. a., In silico studies and evaluation of antiparasitic role of a novel pyruvate phosphate dikinase inhibitor in Leishmania donovani infected macrophages. 2019, 53 (4), 508-514.

28. Tabrez, S.; Rahman, F.; Ali, R.; Alouffi, A. S.; Akand, S. K.; Alshehri, B. M.; Alshammari, F. A.; Alam, A.; Alaidarous, M. A.; Banawas, S.; Dukhyil, A. A. B.; Rub, A., Cynaroside inhibits Leishmania donovani UDP-galactopyranose mutase and induces reactive oxygen species to exert antileishmanial response. Bioscience reports 2020.

29. Kashif, M.; Tabrez, S.; Husein, A.; Arish, M.; Kalaiarasan, P.; Manna, P. P.; Subbarao, N.; Akhter, Y.; Rub, A., Identification of novel inhibitors against UDPgalactopyranose mutase to combat leishmaniasis. J Cell Biochem 2018, 119 (3), 2653-2665. 
30. Kashif, M.; Hira, S. K.; Upadhyaya, A.; Gupta, U.; Singh, R.; Paladhi, A.; Khan, F. I.; Rub, A.; Manna, P. P., In silico studies and evaluation of antiparasitic role of a novel pyruvate phosphate dikinase inhibitor in Leishmania donovani infected macrophages. Int J Antimicrob Agents 2019, 53 (4), 508-514.

31. Zimmermann, L.; Stephens, A.; Nam, S. Z.; Rau, D.; Kübler, J.; Lozajic, M.; Gabler, F.; Söding, J.; Lupas, A. N.; Alva, V., A Completely Reimplemented MPI Bioinformatics Toolkit with a New HHpred Server at its Core. Journal of molecular biology 2018, 430 (15), 2237-2243.

32. Sali, A.; Blundell, T. L., Comparative protein modelling by satisfaction of spatial restraints. Journal of molecular biology 1993, 234 (3), 779-815.

33. Laskowski, R. A.; Rullmannn, J. A.; MacArthur, M. W.; Kaptein, R.; Thornton, J. M., AQUA and PROCHECK-NMR: programs for checking the quality of protein structures solved by NMR. Journal of biomolecular NMR 1996, 8 (4), 477-86.

34. O'Boyle, N. M.; Banck, M.; James, C. A.; Morley, C.; Vandermeersch, T.; Hutchison, G. R., Open Babel: An open chemical toolbox. Journal of cheminformatics 2011, 3, 33.

35. Rappé, A. K.; Casewit, C. J.; Colwell, K.; Goddard III, W. A.; Skiff, W. M. J. J. o. t. A. c. s., UFF, a full periodic table force field for molecular mechanics and molecular dynamics simulations. 1992, 114 (25), 10024-10035.

36. Lagunin, A.; Zakharov, A.; Filimonov, D.; Poroikov, V., QSAR Modelling of Rat Acute Toxicity on the Basis of PASS Prediction. Molecular informatics 2011, 30 (2-3), 241-50.

37. Daina, A.; Michielin, O.; Zoete, V., SwissADME: a free web tool to evaluate pharmacokinetics, drug-likeness and medicinal chemistry friendliness of small molecules. Sci Rep 2017, 7, 42717.

38. Lipinski, C. A., Lead- and drug-like compounds: the rule-of-five revolution. Drug discovery today. Technologies 2004, 1 (4), 337-41.

39. Zhao, Y. H.; Abraham, M. H.; Le, J.; Hersey, A.; Luscombe, C. N.; Beck, G.; Sherborne, B.; Cooper, I., Rate-limited steps of human oral absorption and QSAR studies. Pharmaceutical research 2002, 19 (10), 1446-57.

40. Mokhnache, K.; Madoui, S.; Khither, H.; Charef, N., Drug-Likeness and Pharmacokinetics of a bis-Phenolic Ligand: Evaluations by Computational Methods. Sch J App Med Sci 2019, 1, 167-173.

41. Ungell, A.-L., In Vitro Absorption Studies and Their Relevance to Absorption from the GI Tract. Drug Development and Industrial Pharmacy 1997, 23 (9), 879-892.

42. Farnsworth, N. R., The role of ethnopharmacology in drug development. Ciba Foundation symposium 1990, 154, 2-11; discussion 11-21.

43. Chouhan, G.; Islamuddin, M.; Sahal, D.; Afrin, F., Exploring the role of medicinal plant-based immunomodulators for effective therapy of leishmaniasis. Frontiers in immunology 2014, 5, 193.

44. Tahir, A. E.; Ibrahim, A. M.; Satti, G. M.; Theander, T. G.; Kharazmi, A.; Khalid, S. A. J. P. R. A. I. J. D. t. P., The potential antileishmanial activity of some Sudanese medicinal plants. Phytotherapy Research: An International Journal Devoted to Pharmacological and Toxicological Evaluation of Natural Product Derivatives 1998, 12 (8), 576-579.

45. Rai, S. P.; Prasad, M. S.; Singh, K., Evaluation of the antifungal activity of the potent fraction of hexane extract obtained from the bark of Acacia nilotica. IJSR 2014, 3, 730-8.

46. Ambasta, S. P., The Useful Plants of India. Publication and information Directorate, Council of Scientific \& Industrial Research: New Delhi, India, 1994. 
47. Sadiq, M. B.; Hanpithakpong, W.; Tarning, J.; Anal, A. K., Screening of phytochemicals and in vitro evaluation of antibacterial and antioxidant activities of leaves, pods and bark extracts of Acacia nilotica (L.) Del. Industrial Crops and Products 2015, 77, 873-882. 48. Borges, A.; Ferreira, C.; Saavedra, M. J.; Simões, M., Antibacterial activity and mode of action of ferulic and gallic acids against pathogenic bacteria. Microbial drug resistance (Larchmont, N.Y.) 2013, 19 (4), 256-65.

49. $\quad$ Fatima, F.; Khalid, A.; Nazar, N.; Abdalla, M.; Mohomed, H.; Toum, A. M.; Magzoub, M.; Alı, M. S., In vitro assessment of anti - cutaneous leishmaniasis activity of some Sudanese plants. Turkiye parazitolojii dergisi 2005, 29 (1), 3-6.

50. Goto, Y.; Bhatia, A.; Raman, V. S.; Vidal, S. E.; Bertholet, S.; Coler, R. N.; Howard, R. F.; Reed, S. G., Leishmania infantum sterol 24-c-methyltransferase formulated with MPL-SE induces cross-protection against L. major infection. Vaccine 2009, 27 (21), 2884-90.

51. Baiocco, P.; Colotti, G.; Franceschini, S.; Ilari, A., Molecular basis of antimony treatment in leishmaniasis. Journal of medicinal chemistry 2009, 52 (8), 2603-12.

52. Ong, H. B.; Sienkiewicz, N.; Wyllie, S.; Fairlamb, A. H., Dissecting the metabolic roles of pteridine reductase 1 in Trypanosoma brucei and Leishmania major. The Journal of biological chemistry 2011, 286 (12), 10429-38.

53. Scotti, L.; Ishiki, H.; Mendonça Júnior, F. J.; Da Silva, M. S.; Scotti, M. T., In-silico analyses of natural products on leishmania enzyme targets. Mini reviews in medicinal chemistry 2015, 15 (3), 253-69.

54. Mielke, H.; Strickland, J.; Jacobs, M. N.; Mehta, J. M., Biometrical evaluation of the performance of the revised OECD Test Guideline 402 for assessing acute dermal toxicity. Regulatory toxicology and pharmacology : RTP 2017, 89, 26-39.

55. Yu, J. S.; Cui, W., Proliferation, survival and metabolism: the role of PI3K/AKT/mTOR signalling in pluripotency and cell fate determination. Development (Cambridge, England) 2016, 143 (17), 3050-60.

56. Das, A.; Jawed, J. J.; Das, M. C.; Sandhu, P.; De, U. C.; Dinda, B.; Akhter, Y.; Bhattacharjee, S., Antileishmanial and immunomodulatory activities of lupeol, a triterpene compound isolated from Sterculia villosa. Int J Antimicrob Agents 2017, 50 (4), 512-522. Figures legends:

Figure 1: A. nilotica bark methanolic extract inhibits the growth and proliferation of $L$. donovani promastigotes (A) $2 \times 10^{6}$ stationary phase $L$ donovani promastigotes were treated with different concentration of A nilotica methanolic plants extracts, with miltefosine as standard drug and control (without any treatment). Each point is statistically significant as compare to control. (B)2 X $10^{6}$ stationary phase $L$ donovani promastigotes were treated with different concentration of A nilotica methanolic plant extract fraction and miltefosine, $\mathrm{IC}_{50}$ was determined as described in the methods. Each point represents the mean \pm SE of the samples in triplicate.(C) Image of the promastigote morphological changes in the treated samples at 
different concentration of $A$ nilotica fraction and miltefosine treated samples.(D) Stationary phase $L$ donovani promastigotes were incubated with different concentration of $A$ nilotica, with miltefosine and DMSO (solvent control). And the growth reversal was analyzed as described in

methods. ${ }^{* * *} \mathrm{P}<0.001$ with respect to parasite control. Anti-promastigote efficacy of $A$ nilotica fractions.

Figure 2: A. nilotica bark methanolic extract decreases the intra-macrophagic parasites (A). Anti-amastigote efficacy determination.THP-1 differentiated macrophages was parasitized in 1:10 ratio with stationary phase promastigotes and then treated with different concentration of A nilotica fraction. Percent reduction in the parasite load was determined as described in the method. ${ }^{* * *} \mathrm{P}<0.001$, value was statistically significant as compare to control.(B).THP-1 differentiated macrophages were treated with different concentration of $A$ nilotica and miltefosine ( 0 to $1000 \mu \mathrm{g} / \mathrm{ml}$ ) and cell viability was ascertained by MTT assay. (C). Microscopic $L$ donovaniinfected macrophage images depict parasitized, treated THP-1 differentiated macrophages stained with modified Giemsa stained. The images were captured at 100X under oil immersion. The arrow indicates internalized parasites

Figure 3: A. nilotica major chemical constituents inhibit SMT of $L$. donovani in silico

(A) Lupeol blocking the binding pocket of SMT enzyme. (B) 2D plot showing interactions between receptor and ligand.(C) 9,12-Octadecadienoic acid blocking the binding pocket of SMT enzyme. (D) 2D plot showing interactions between receptor and ligand. (E) 6-Octadecenoic acid blocking the binding pocket of SMT enzyme. (F) 2D plot showing interactions between receptor and ligand. (G) 13-Docosenoic acid blocking the binding pocket of SMT enzyme. (H) 2D plot showing interactions between receptor and ligand.

Figure 4: A. nilotica major chemical constituents inhibit TR of $L$. donovani in silico 
(A) Lupeol blocking the binding pocket of TR enzyme. (B) 2D plot showing interactions between receptor and ligand. (C) 9,12-Octadecadienoic acid blocking the binding pocket of TR enzyme. (D) 2D plot showing interactions between receptor and ligand. (E) 6-Octadecenoic acid blocking the binding pocket of TR enzyme. (F) 2D plot showing interactions between receptor and ligand. (G) 13-Docosenoic acid blocking the binding pocket of TR enzyme. (H) 2D plot showing interactions between receptor and ligand.

Figure 5: A. nilotica major chemical constituents inhibit PTR1 of L. donovani in silico (A) Lupeol blocking the binding pocket of PTR1 (PDB ID: 2XOX) enzyme. (B) 2D plot showing interactions between receptor and ligand. (C) 9,12-Octadecadienoic acid blocking the binding pocket of PTR1 (PDB ID: 2XOX) enzyme. (D) 2D plot showing interactions between receptor and ligand. (E) 6-Octadecenoic acid blocking the binding pocket of PTR1 (PDB ID: 2XOX) enzyme. (F) 2D plot showing interactions between receptor and ligand. (G) 13-Docosenoic acid blocking the binding pocket of PTR1 (PDB ID: 2XOX) enzyme. (H) 2D plot showing interactions between receptor and ligand.

Figure 6: A. nilotica major chemical constituents inhibit APRT of $L$. donovani in silico

(A) Lupeol blocking the binding pocket of APRT (PDB ID: 1QB7) enzyme. (B) 2D plot showing interactions between receptor and ligand. (C) 9,12-Octadecadienoic acid blocking the binding pocket of APRT (PDB ID: 1QB7) enzyme. (D) 2D plot showing interactions between receptor and ligand. (E) 6-Octadecenoic acid blocking the binding pocket of APRT (PDB ID: 1QB7) enzyme. (F) 2D plot showing interactions between receptor and ligand. (G) 13Docosenoic acid blocking the binding pocket of APRT (PDB ID: 1QB7) enzyme. (H) 2D plot showing interactions between receptor and ligand. 


\section{Tables legends:}

Table 1: Table 1: TLC-bioautography identification and GC-MS analysis of A. nilotica bark methanolic extractdepictedkey chemical constituents of extract

Table 2: Molecular docking interaction of abundant medicinal constituents of $A$. nilotica bark methanolic extract shows significant inhibition of L. donovani target proteins

Table 3: Evaluation of physicochemical and ADMET properties show feasibility of usage of the chemical constituents for the treatment of disease

Table 4: Bioactivity prediction of the selected ligands against $L$. donovani by molinspiration Table 5: Acute toxicity shows the lethal dose and extent of toxicity of chemical constituents on rodent models 
$\underline{\text { Tables }}$

Table 1: TLC-bioautography identification and GC-MS analysis of $\boldsymbol{A}$. nilotica bark methanolic extract depicted key chemical constituents of extract

\begin{tabular}{|c|c|c|c|}
\hline S. NO. & $\begin{array}{l}\text { RETENTION } \\
\text { TIME }\end{array}$ & $\%$ AREA & COMPOUND IDENTIFIED \\
\hline 1. & 13.606 & 0.45 & 1H-3A,7-METHANOAZULEN-6-OL \\
\hline 2. & 14.220 & 0.79 & 1H-BENZOCYCLOHEPTENE \\
\hline 3. & 14.290 & 0.32 & $\begin{array}{l}\text { PHENOL, 3,5-BIS(1,1- } \\
\text { DIMETHYLETHYL) }\end{array}$ \\
\hline 4. & 15.277 & 1.49 & DIETHYL PHTHALATE \\
\hline 5. & 16.139 & 0.54 & $\begin{array}{l}\text { 1-(4-ISOPROPYLPHENYL)-2- } \\
\text { METHYLPROPYL ACETATE }\end{array}$ \\
\hline 6. & 18.855 & 5.42 & $\begin{array}{l}\text { HEXADECANOIC ACID, METHYL } \\
\text { ESTER }\end{array}$ \\
\hline 7. & 19.328 & 1.71 & N-HEXADECANOIC ACID \\
\hline 8. & 20.258 & 0.30 & $\begin{array}{l}\text { 13-HEXYL-OXA-CYCLOTRIDEC-10- } \\
\text { EN-2-ONE }\end{array}$ \\
\hline 9. & 20.465 & 9.92 & 9,12-OCTADECADIENOIC ACID \\
\hline 10. & 20.523 & 8.43 & $\begin{array}{l}\text { 6-OCTADECENOIC ACID, METHYL } \\
\text { ESTER }\end{array}$ \\
\hline 11. & 20.761 & 2.81 & METHYL STEARATE \\
\hline 12. & 20.961 & 1.44 & $\begin{array}{l}\text { E,E,Z-1,3,12-NONADECATRIENE-5,14- } \\
\text { DIOL }\end{array}$ \\
\hline 13. & 22.267 & 0.17 & HEXAHYDRO-3-BUTYLPHTHALIDE \\
\hline 14. & 22.311 & 2.86 & $\begin{array}{l}\text { CIS-11-EICOSENOIC ACID, METHYL } \\
\text { ESTER }\end{array}$ \\
\hline 15. & 22.368 & 0.53 & $\begin{array}{l}\text { CIS-13-EICOSENOIC ACID, METHYL } \\
\text { ESTER }\end{array}$ \\
\hline 16. & 22.527 & 1.14 & EICOSANOIC ACID, METHYL ESTER \\
\hline 17. & 23.965 & 34.06 & 13-DOCOSENOIC ACID \\
\hline 18. & 24.161 & 0.84 & DOCOSANOIC ACID \\
\hline 19. & 25.532 & 1.52 & CIS-15-TETRACOSENSAEURE \\
\hline 20. & 25.721 & 0.70 & TETRACOSANOIC ACID \\
\hline 21. & 25.897 & 0.85 & CYCLOPENTADECANONE \\
\hline 22. & 27.325 & 0.34 & OCTACOSANE \\
\hline 23. & 27.885 & 0.83 & 9-OCTADECENAL \\
\hline
\end{tabular}




\begin{tabular}{|l|l|l|l|}
\hline 24. & 33.099 & 2.36 & STIGMASTEROL \\
\hline 25. & $\mathbf{3 6 . 6 7 9}$ & $\mathbf{2 0 . 1 5}$ & LUPEOL \\
\hline
\end{tabular}

Table 2: Molecular docking interaction of abundant medicinal constituents of $\boldsymbol{A}$. nilotica bark methanolic extract shows significant inhibition of $L$. donovani target proteins

\begin{tabular}{|c|c|c|c|c|c|}
\hline S. No. & Proteins & Ligands & $\begin{array}{c}\text { Binding } \\
\text { energy } \\
\text { (Kcal/mol) }\end{array}$ & $\begin{array}{c}\text { pKi } \mathbf{i}_{\text {pred }} \\
(\mu \mathrm{M})\end{array}$ & Interacting Residues \\
\hline \multirow{4}{*}{1.} & \multirow{4}{*}{$\begin{array}{l}\text { Sterol 24- } \\
\quad \text { c- } \\
\text { methytra } \\
\text { nsferase }\end{array}$} & Lupeol & -8.5 & 6.25 & $\begin{array}{c}\text { Lys198, Tyr206, Met210, } \\
\text { Asn215, Pro216, Asn217, } \\
\text { Cys240, Gln242, Leu322, } \\
\text { Ile344, Arg347, Lys348, } \\
\text { Lys351 }\end{array}$ \\
\hline & & $\begin{array}{c}9,12- \\
\text { Octadecadi } \\
\text { enoic acid }\end{array}$ & -5.7 & 4.19 & $\begin{array}{l}\text { Lys198, Cys202, Phe203, } \\
\text { Tyr206, Met210, Asn215, } \\
\text { Asn217, Cys240, Lys241, } \\
\text { Phe259, Gln263, Leu322, } \\
\text { Ile344, Arg347, Lys348, } \\
\text { Lys351 }\end{array}$ \\
\hline & & $\begin{array}{c}\text { 6- } \\
\text { Octadeceno } \\
\text { ic acid }\end{array}$ & -5.7 & 4.19 & $\begin{array}{l}\text { Lys198, Cys202, Phe203, } \\
\text { Tyr206, Met210, Asn215, } \\
\text { Asn217, Cys240, Lys241, } \\
\text { Ala257, Phe259, Ile261, } \\
\text { Gln263, Leu322, Ile344, } \\
\text { Arg347, Lys348, Lys351 }\end{array}$ \\
\hline & & $\begin{array}{c}13- \\
\text { Docosenoic } \\
\text { acid }\end{array}$ & -5.6 & 4.12 & $\begin{array}{l}\text { Lys198, Gly200, Cys202, } \\
\text { Phe203, Tyr206, Met210, } \\
\text { Asn215, Pro216, Asn217, } \\
\text { Lys241, Phe259, Gln263, } \\
\text { Leu322, Ile344, Arg347, } \\
\text { Lys348, Lys351 }\end{array}$ \\
\hline \multirow{3}{*}{2.} & \multirow{3}{*}{$\begin{array}{l}\text { Trypanot } \\
\text { hione } \\
\text { reductase }\end{array}$} & Lupeol & -8.4 & 6.12 & $\begin{array}{c}\text { Gly197, Tyr198, Phe230, } \\
\text { Val332, Met333, Leu334, } \\
\text { His359, Val362, Cys364, } \\
\text { Gly374 }\end{array}$ \\
\hline & & $\begin{array}{c}9,12- \\
\text { Octadecadi } \\
\text { enoic acid }\end{array}$ & -4.9 & 3.60 & $\begin{array}{l}\text { Tyr198, Phe230, Val332, } \\
\text { Met333, Cys364, Gly376 }\end{array}$ \\
\hline & & $\begin{array}{c}\text { 6- } \\
\text { Octadeceno } \\
\text { ic acid, }\end{array}$ & -4.9 & 3.60 & $\begin{array}{l}\text { Gly197, Tyr198, Gly229, } \\
\text { Phe230, Val332, Met333, } \\
\text { Leu334, Cys362, Cys364, } \\
\text { Gly374, Cys375, Gly376 }\end{array}$ \\
\hline
\end{tabular}




\begin{tabular}{|c|c|c|c|c|c|}
\hline & & $\begin{array}{l}13- \\
\text { Docosenoic } \\
\text { acid }\end{array}$ & -4.7 & 3.46 & $\begin{array}{l}\text { Gly197, Tyr198, Phe230, } \\
\text { Gly286, Val332, Met333, } \\
\text { Leu334, Lys361, Cys362, } \\
\text { Cys364, Gly374, Cys375, } \\
\text { Gly376 }\end{array}$ \\
\hline \multirow[t]{4}{*}{3.} & \multirow{4}{*}{$\begin{array}{l}\text { Pteridine } \\
\text { reductase }\end{array}$} & Lupeol & -7.9 & 5.81 & $\begin{array}{c}\text { His38, Gln63, Ala64, } \\
\text { Asp65, Lys71, Ala77, } \\
\text { Val83, Lys87, Arg88, } \\
\text { Asp91 }\end{array}$ \\
\hline & & $\begin{array}{c}9,12- \\
\text { Octadecadi } \\
\text { enoic acid }\end{array}$ & -5.3 & 3.90 & $\begin{array}{c}\text { Phe86, Lys87, Ala90, } \\
\text { Ala94, Lys156, Ala157, } \\
\text { His160, Arg161 }\end{array}$ \\
\hline & & $\begin{array}{c}\text { 6- } \\
\text { Octadeceno } \\
\text { ic acid }\end{array}$ & -4.4 & 3.24 & $\begin{array}{l}\text { Lys71, Ala77, Val83, } \\
\text { Lys87, Arg88, Leu92 }\end{array}$ \\
\hline & & $\begin{array}{c}13- \\
\text { Docosenoic } \\
\text { acid, }\end{array}$ & -5.4 & 3.97 & $\begin{array}{l}\text { Val83, Phe86, Lys87, } \\
\text { Ala90, Ala94, Lys156, } \\
\text { Ala157, His160, Arg161 }\end{array}$ \\
\hline \multirow{4}{*}{4.} & \multirow{4}{*}{$\begin{array}{l}\text { Adenine } \\
\text { phosphor } \\
\text { ybosyl } \\
\text { transferas } \\
\text { e }\end{array}$} & Lupeol & -6.2 & 4.56 & $\begin{array}{c}\text { Pro36, Arg37, Arg82, } \\
\text { Lys103, Glu127, Asp146, } \\
\text { Ala150, Thr151, Glu152, } \\
\text { Gly153, Thr154 }\end{array}$ \\
\hline & & $\begin{array}{l}9,12- \\
\text { Octadecadi } \\
\text { enoic acid }\end{array}$ & -6.1 & 4.49 & $\begin{array}{l}\text { Trp29, Arg37, Val39, } \\
\text { Pro40, Arg41, Phe42, } \\
\text { Ala43, Arg82, Val148, } \\
\text { Ala150, Leu176, Ile178, } \\
\text { Leu181, Asp206, Leu209 }\end{array}$ \\
\hline & & $\begin{array}{c}\text { 6- } \\
\text { Octadeceno } \\
\text { ic acid }\end{array}$ & -5.9 & 4.34 & $\begin{array}{c}\text { Arg37, Val39, Pro40, } \\
\text { Arg41, Phe42, Ala43, } \\
\text { Arg82, Val148, Ala150, } \\
\text { Leu176, Ile178, Phe180, } \\
\text { Leu181, Asp206 }\end{array}$ \\
\hline & & $\begin{array}{l}13- \\
\text { Docosenoic } \\
\text { acid }\end{array}$ & -5.9 & 4.34 & $\begin{array}{c}\text { Arg37, Val39, Pro40, } \\
\text { Arg41, Phe42, Ala43, } \\
\text { Arg82, Val148, Ala150, } \\
\text { Leu176, Ile178, Phe180, } \\
\text { Leu181, Asp206, Leu209 }\end{array}$ \\
\hline
\end{tabular}


Table 3: Evaluation of physico-chemical and ADMET properties show feasibility of usage of the chemical constituents for the treatment of disease

\begin{tabular}{|c|c|c|c|c|c|c|c|c|c|c|c|c|}
\hline $\begin{array}{c}\text { Ligan } \\
\text { ds }\end{array}$ & $\begin{array}{c}\text { MW } \\
(<\mathbf{5 0} \\
\mathbf{0})\end{array}$ & $\begin{array}{c}\text { HB } \\
\text { D } \\
(<5)\end{array}$ & $\begin{array}{c}\text { HB } \\
\text { A } \\
(<10 \\
)\end{array}$ & $\begin{array}{l}\text { Log } \\
\text { Po/ } \\
\text { w } \\
\text { (Lip } \\
\text { ophi } \\
\text { licit } \\
\text { y) }\end{array}$ & $\begin{array}{r}\text { TPSA } \\
(\leq 140)\end{array}$ & $\begin{array}{c}\text { Absor } \\
\text { ption } \\
\text { perce } \\
\text { ntage } \\
(\text { AB \% } \\
\text { ) } \\
(>\mathbf{5 0} \\
\%)\end{array}$ & $\begin{array}{c}\text { Druglik } \\
\text { ness } \\
\text { (Lipinsk } \\
\text { i } \\
\text { violatio } \\
\text { ns) }\end{array}$ & $\begin{array}{c}\text { GI- } \\
\text { abs } \\
\text { orp } \\
\text { tion }\end{array}$ & $\begin{array}{c}\text { BB } \\
\text { B } \\
\text { per } \\
\text { me } \\
\text { ant }\end{array}$ & $\begin{array}{l}\text { CYP } \\
\text { 1A2 } \\
\text { inhi } \\
\text { bitor }\end{array}$ & $\begin{array}{c}\text { Bioa } \\
\text { vail } \\
\text { abili } \\
\text { ty } \\
\text { scor } \\
\text { e }\end{array}$ & $\begin{array}{c}\text { Water } \\
\text { solubil } \\
\text { ity } \\
\text { (Log } \\
\text { S) }\end{array}$ \\
\hline Lupeol & $\begin{array}{c}426 . \\
39\end{array}$ & 1 & 1 & 4.76 & 20.23 & 102.02 & $\begin{array}{c}\text { Yes; } 1 \\
\text { violation }\end{array}$ & $\begin{array}{l}\text { Lo } \\
\mathrm{W}\end{array}$ & No & No & 0.55 & $\begin{array}{c}-8.64 \\
\text { (Poorl } \\
\text { y } \\
\text { Solubl } \\
\text { e) }\end{array}$ \\
\hline $\begin{array}{l}9,12- \\
\text { Octade } \\
\text { cadien } \\
\text { oic } \\
\text { acid }\end{array}$ & $\begin{array}{c}294 . \\
48\end{array}$ & 0 & 2 & 4.61 & 26.30 & 99.93 & $\begin{array}{c}\text { Yes; } 1 \\
\text { violation }\end{array}$ & $\underset{\mathrm{h}}{\mathrm{Hig}}$ & No & Yes & 0.55 & $\begin{array}{l}-4.97 \\
\text { (Mode } \\
\text { rately } \\
\text { Solubl } \\
\text { e) }\end{array}$ \\
\hline $\begin{array}{c}\text { 6- } \\
\text { Octade } \\
\text { cenoic } \\
\text { acid }\end{array}$ & $\begin{array}{c}296 . \\
50\end{array}$ & 0 & 2 & 4.73 & 26.30 & 99.93 & $\begin{array}{c}\text { Yes; } 1 \\
\text { violation }\end{array}$ & $\underset{\mathrm{h}}{\mathrm{Hig}}$ & No & Yes & 0.55 & $\begin{array}{l}-5.13 \\
\text { (Mode } \\
\text { rately } \\
\text { Solubl } \\
\text { e) }\end{array}$ \\
\hline $\begin{array}{c}13- \\
\text { Docos } \\
\text { enoic } \\
\text { acid }\end{array}$ & $\begin{array}{c}352 . \\
60\end{array}$ & 0 & 2 & 5.65 & 26.30 & 99.93 & $\begin{array}{c}\text { Yes; } 1 \\
\text { violation }\end{array}$ & $\begin{array}{l}\text { Lo } \\
W\end{array}$ & No & Yes & 0.55 & $\begin{array}{c}-6.58 \\
\text { (Poorl } \\
y \\
\text { Solubl } \\
\text { e) }\end{array}$ \\
\hline
\end{tabular}


Table 4: Bioactivity prediction of the selected ligands against $L$. donovani by molinspiration

\begin{tabular}{|l|c|c|c|c|c|c|}
\hline \multicolumn{1}{|c|}{ Ligands } & $\begin{array}{c}\text { GPC } \\
\mathbf{R} \\
\text { ligan } \\
\mathbf{d}\end{array}$ & $\begin{array}{c}\text { Ion } \\
\text { channel } \\
\text { modulator }\end{array}$ & $\begin{array}{c}\text { Kinase } \\
\text { Inhibito } \\
\mathbf{r}\end{array}$ & $\begin{array}{c}\text { Nuclear } \\
\text { receptor } \\
\text { ligand }\end{array}$ & $\begin{array}{c}\text { Protease } \\
\text { Inhibito } \\
\mathbf{r}\end{array}$ & $\begin{array}{c}\text { Enzyme } \\
\text { Inhibito } \\
\mathbf{r}\end{array}$ \\
\hline Lupeol & 0.27 & 0.11 & -0.42 & 0.85 & 0.15 & 0.52 \\
\hline 9,12- Octadecadienoic acid & 0.15 & 0.07 & -0.20 & 0.14 & 0.03 & 0.23 \\
\hline 6-Octadecenoic acid & 0.03 & -0.03 & -0.25 & 0.06 & -0.02 & 0.12 \\
\hline 13-Docosenoic acid & 0.07 & -0.02 & -0.17 & 0.10 & 0.07 & 0.10 \\
\hline
\end{tabular}

Table 5: Acute toxicity shows the lethal dose and extent of toxicity of chemical constituents on rodent models

\begin{tabular}{|c|c|c|c|c|c|c|}
\hline $\begin{array}{c}\text { S. } \\
\text { No. }\end{array}$ & Ligands & $\begin{array}{c}\text { Rat Oral } \\
\mathbf{L D 5 0} \\
(\mathbf{m g} / \mathbf{k g})\end{array}$ & $\begin{array}{c}\text { Rat IV } \\
\mathbf{L D 5 0} \\
(\mathbf{m g} / \mathbf{k g})\end{array}$ & $\begin{array}{c}\text { Rat SC } \\
\mathbf{L D 5 0} \\
(\mathbf{m g} / \mathbf{k g})\end{array}$ & $\begin{array}{c}\text { Rat IP } \\
\text { LD50 } \\
(\mathbf{m g} / \mathbf{k g})\end{array}$ & $\begin{array}{c}\text { OECD } \\
\text { chemical } \\
\text { classification }\end{array}$ \\
\hline 1. & Lupeol & 2888,000 & 5,867 & 786,900 & 1684,000 & Class 5 \\
\hline 2. & $\begin{array}{c}9,12- \\
\text { Octadecadienoic } \\
\text { acid }\end{array}$ & 8747,000 & 309,300 & 9261,000 & 4673,000 & Non-Toxic \\
\hline 3. & $\begin{array}{c}\text { 6-Octadecenoic } \\
\text { acid }\end{array}$ & 7813,000 & 381,700 & 7007,000 & 3028,000 & Non-Toxic \\
\hline 4. & $\begin{array}{c}\text { 13-Docosenoic } \\
\text { acid }\end{array}$ & 9279,000 & 428,600 & 1,1160000 & 5206,000 & Non-Toxic \\
\hline
\end{tabular}





\section{Figures}

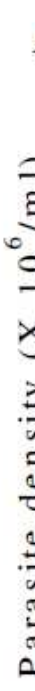

B.

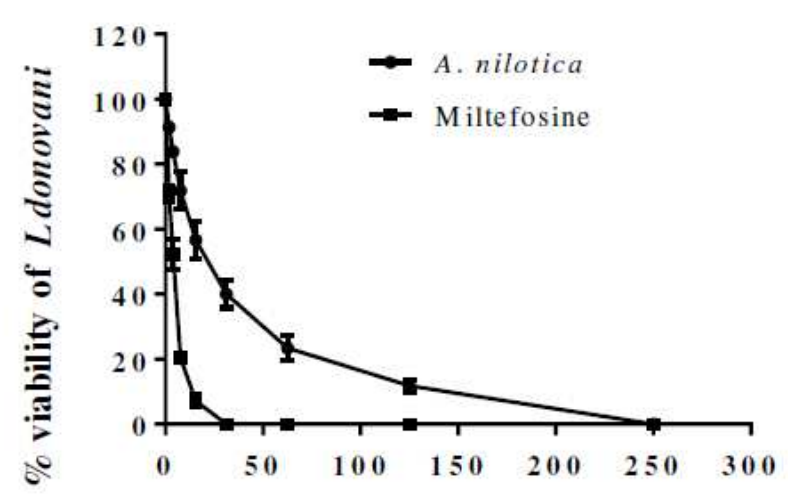

Concentration $(\mu \mathrm{g} / \mathrm{ml})$
C.
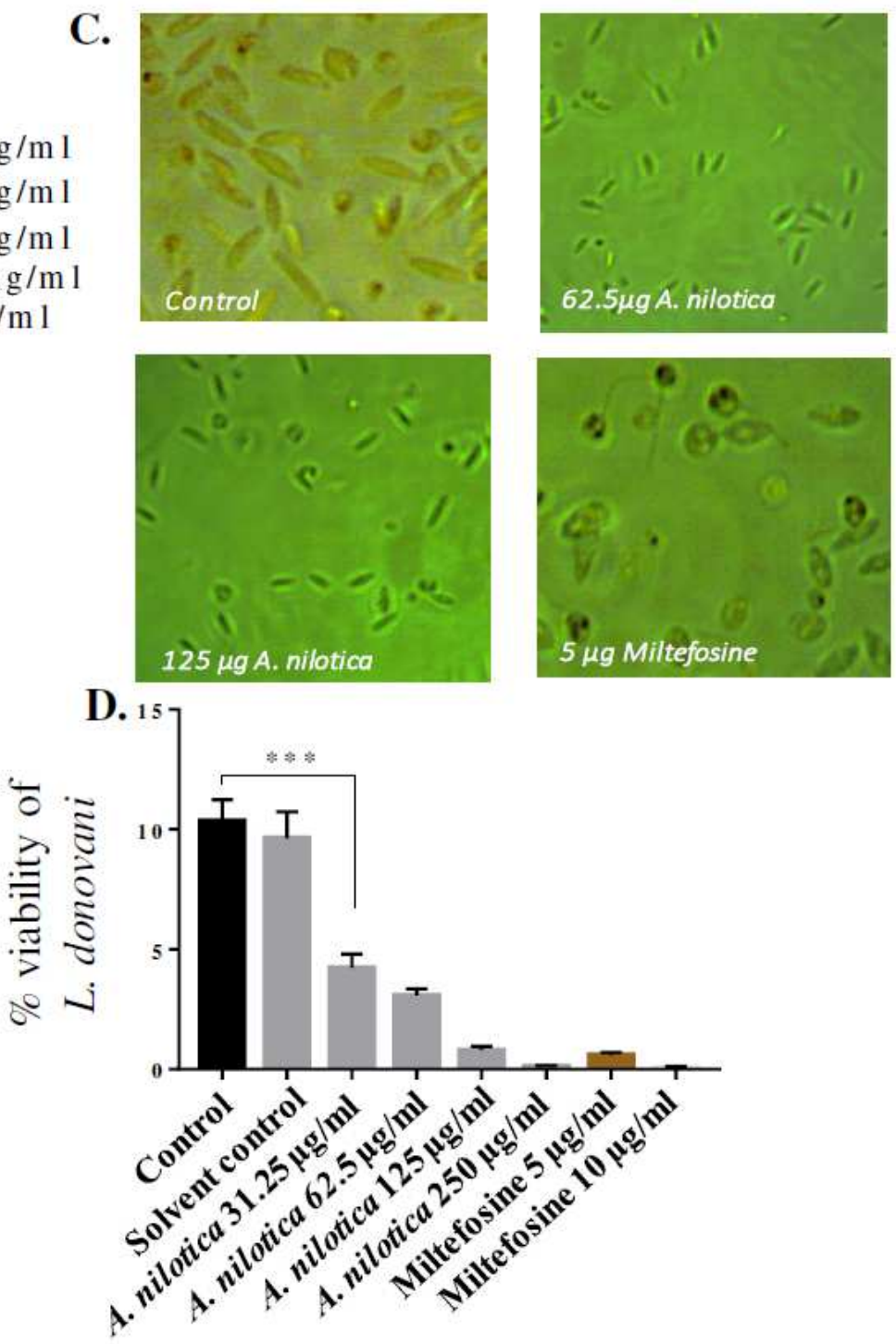

\section{Figure 1}

A. nilotica bark methanolic extract inhibits the growth and proliferation of L. donovani promastigotes (A) $2 \times 106$ stationary phase $L$ donovani promastigotes were treated with different concentration of $A$ nilotica methanolic plants extracts, with miltefosine as standard drug and control (without any treatment). Each point is statistically significant as compare to control. (B) $2 \times 106$ stationary phase $L$ donovani promastigotes were treated with different concentration of A nilotica methanolic plant extract fraction and miltefosine, IC50 was determined as described in the methods. Each point represents the mean + SE of the samples in triplicate.(C) Image of the promastigote morphological changes in the treated samples at different concentration of A nilotica fraction and miltefosine treated samples.(D) Stationary phase $L$ donovani promastigotes were incubated with different concentration of A nilotica, with miltefosine and DMSO (solvent control). And the growth reversal was analyzed as described in methods. ${ }^{* \star *} \mathrm{P}<0.001$ with respect to parasite control. Anti-promastigote efficacy of A nilotica fractions. 


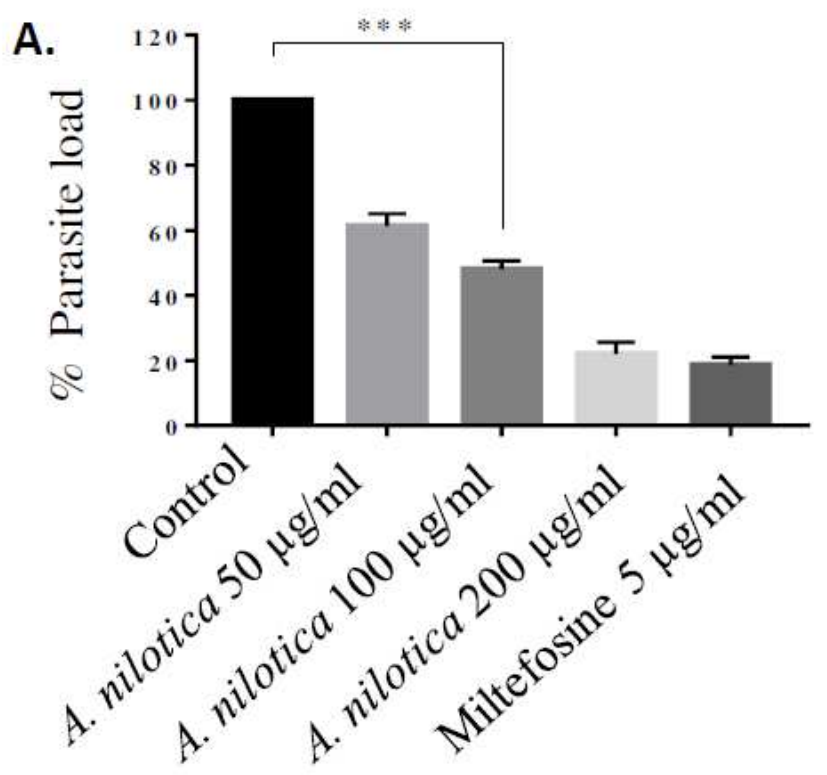

B.

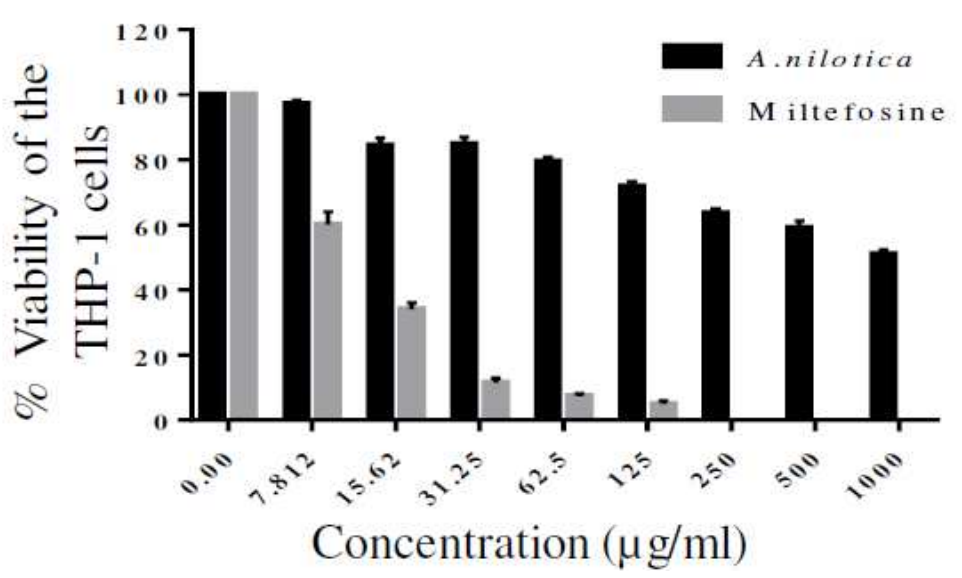

\section{Figure 2}

A. nilotica bark methanolic extract decreases the intra-macrophagic parasites (A). Anti-amastigote efficacy determination.THP-1 differentiated macrophages was parasitized in 1:10 ratio with stationary phase promastigotes and then treated with different concentration of A nilotica fraction. Percent reduction in the parasite load was determined as described in the method. ${ }^{\star} * \star P<0.001$, value was statistically significant as compare to control.(B).THP-1 differentiated macrophages were treated with different concentration of A nilotica and miltefosine $(0$ to $1000 \mu \mathrm{g} / \mathrm{ml})$ and cell viability was ascertained by MTT assay. (C). Microscopic $L$ donovaniinfected macrophage images depict parasitized, treated THP1 differentiated macrophages stained with modified Giemsa stained. The images were captured at $100 \mathrm{X}$ under oil immersion. The arrow indicates internalized parasites 


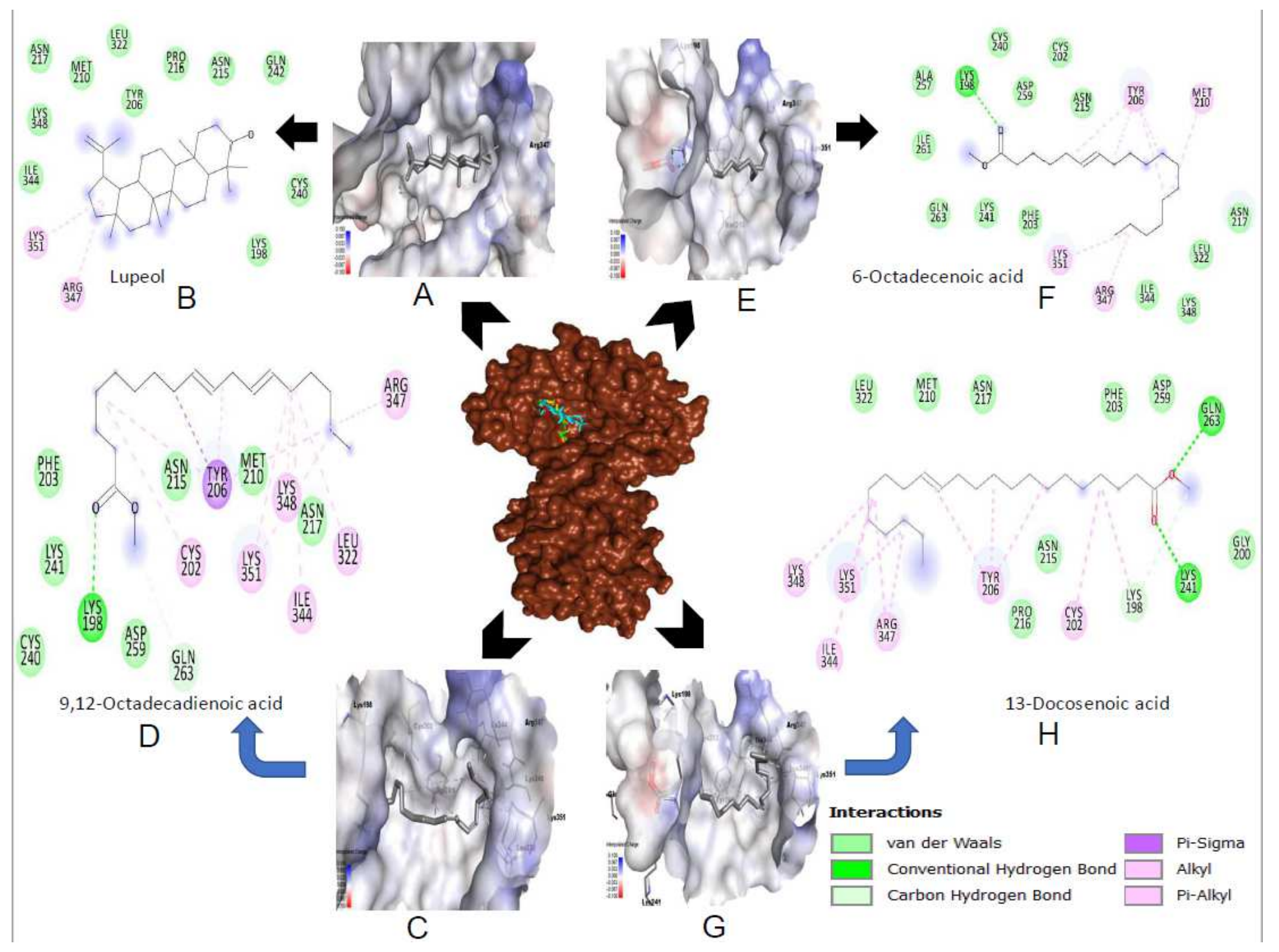

\section{Figure 3}

A. nilotica major chemical constituents inhibit SMT of L. donovani in silico (A) Lupeol blocking the binding pocket of SMT enzyme. (B) 2D plot showing interactions between receptor and ligand.(C) 9,12Octadecadienoic acid blocking the binding pocket of SMT enzyme. (D) 2D plot showing interactions between receptor and ligand. (E) 6-Octadecenoic acid blocking the binding pocket of SMT enzyme. (F) 2D plot showing interactions between receptor and ligand. (G) 13-Docosenoic acid blocking the binding pocket of SMT enzyme. $(\mathrm{H})$ 2D plot showing interactions between receptor and ligand. 
T178

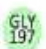

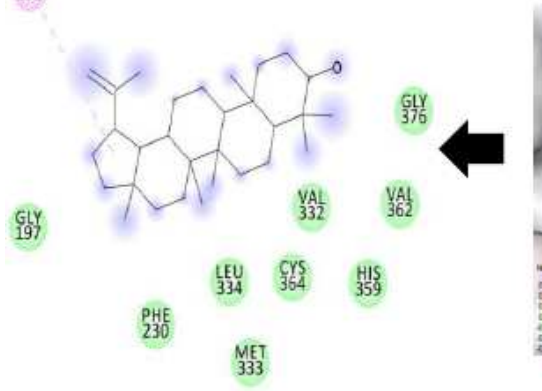

Lupeol

B

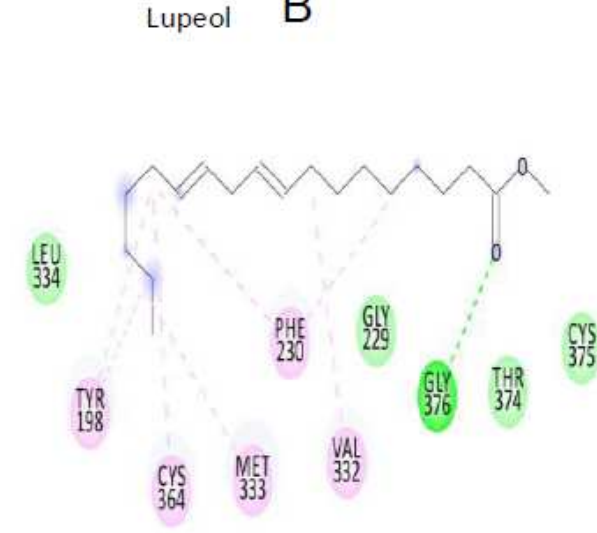

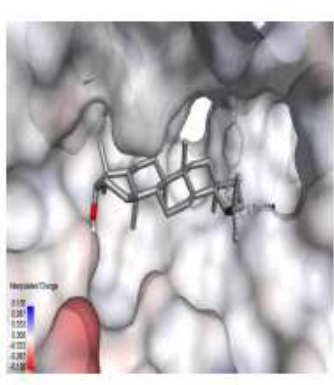

A $P$

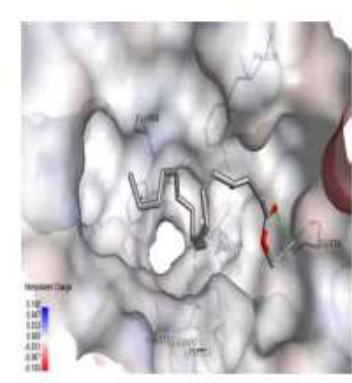

E

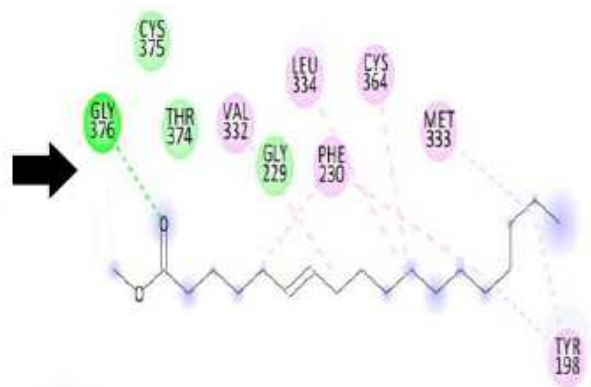

F 6-Octadecenoic acid
9,12-Octadecadienoic acid

D

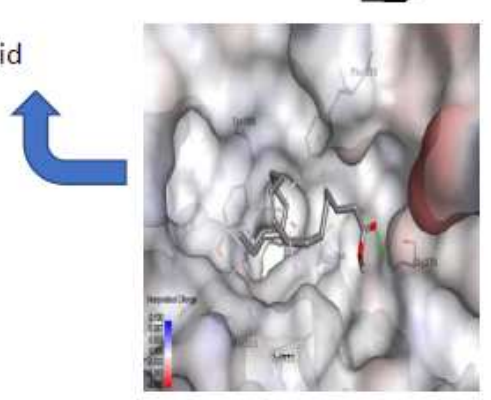

C
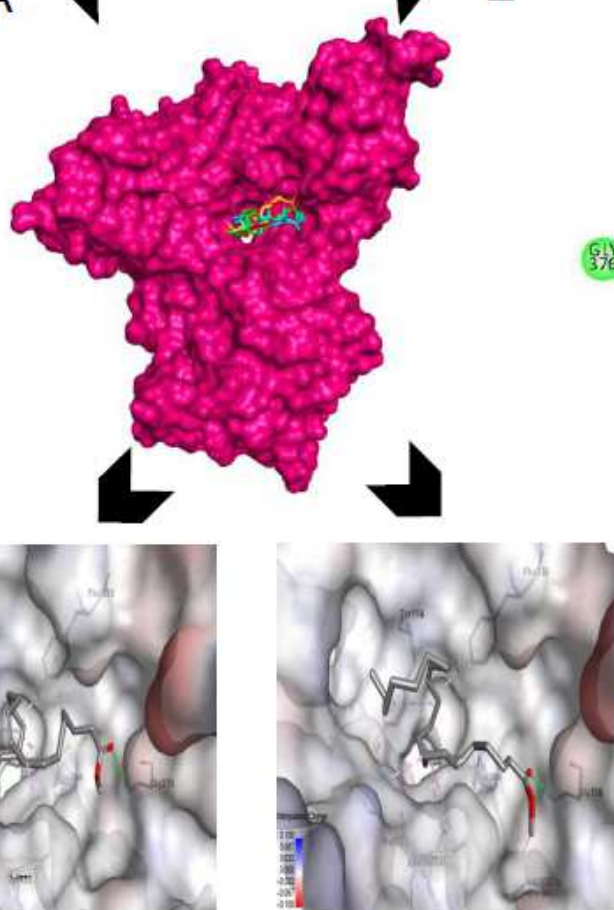

G (3i⿱

TH7

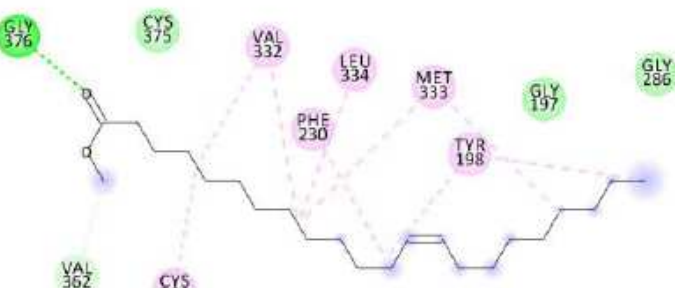

VAL
362
CYS

361

13-Docosenoic acid

$\mathrm{H}$

Interactions

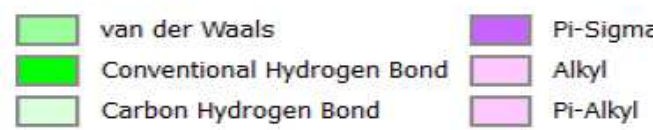

Pi-Alkyl

\section{Figure 4}

A. nilotica major chemical constituents inhibit TR of L. donovani in silico (A) Lupeol blocking the binding pocket of TR enzyme. (B) 2D plot showing interactions between receptor and ligand. (C) 9,12Octadecadienoic acid blocking the binding pocket of TR enzyme. (D) 2D plot showing interactions between receptor and ligand. (E) 6-Octadecenoic acid blocking the binding pocket of TR enzyme. (F) 2D plot showing interactions between receptor and ligand. (G) 13-Docosenoic acid blocking the binding pocket of TR enzyme. $(H)$ 2D plot showing interactions between receptor and ligand. 


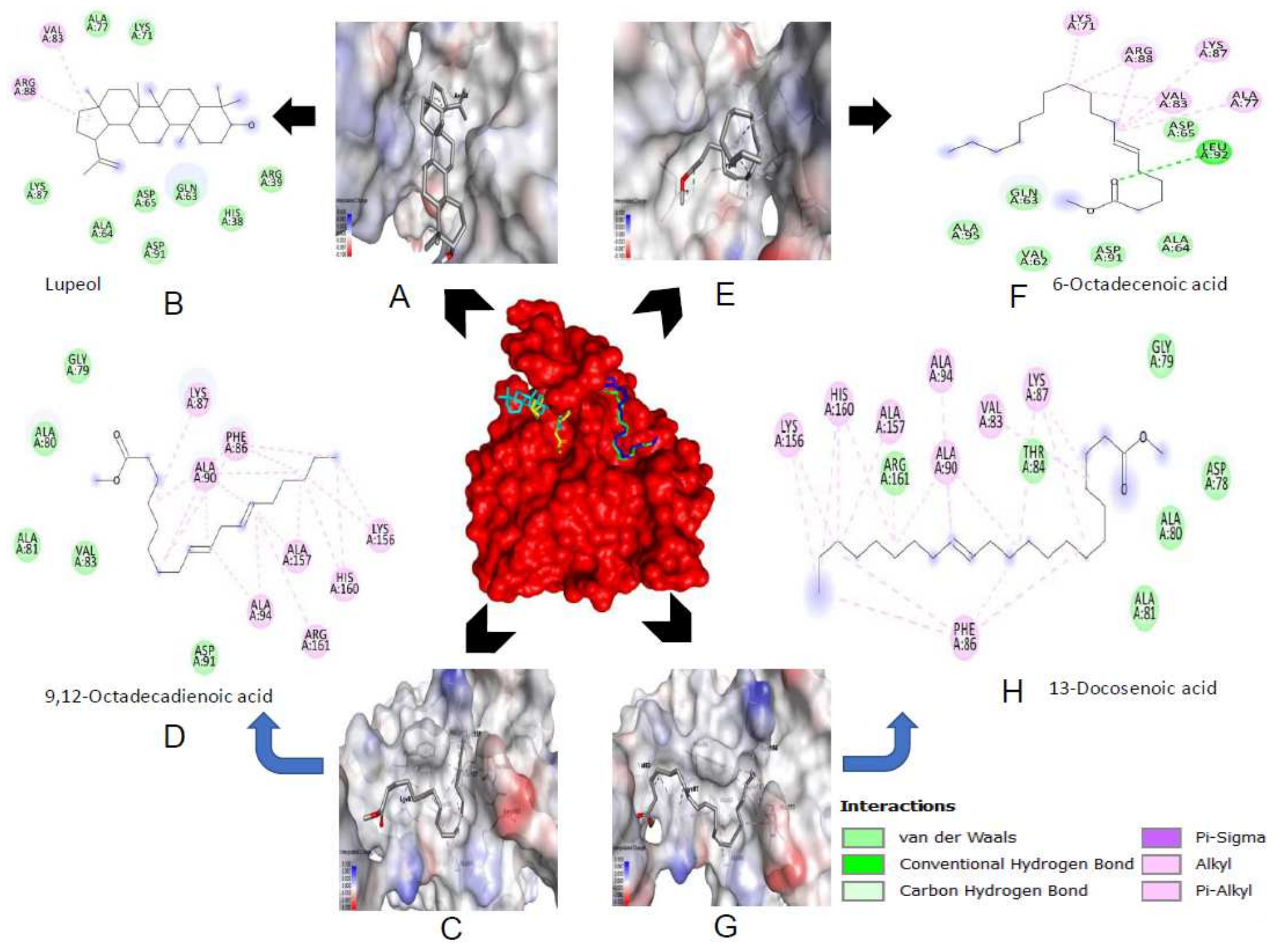

\section{Figure 5}

A. nilotica major chemical constituents inhibit PTR1 of L. donovani in silico (A) Lupeol blocking the binding pocket of PTR1 (PDB ID: 2XOX) enzyme. (B) 2D plot showing interactions between receptor and ligand. (C) 9,12-Octadecadienoic acid blocking the binding pocket of PTR1 (PDB ID: 2XOX) enzyme. (D) 2D plot showing interactions between receptor and ligand. (E) 6-Octadecenoic acid blocking the binding pocket of PTR1 (PDB ID: 2XOX) enzyme. (F) 2D plot showing interactions between receptor and ligand. (G) 13-Docosenoic acid blocking the binding pocket of PTR1 (PDB ID: 2XOX) enzyme. (H) 2D plot showing interactions between receptor and ligand. 


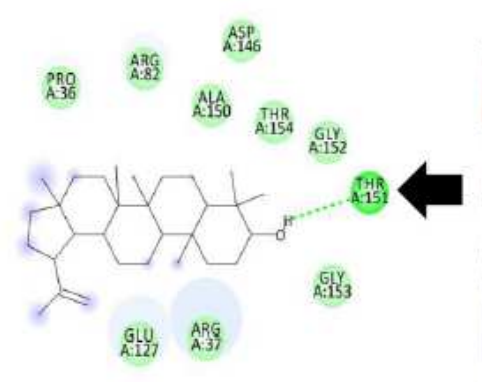

A.103

Lupeol

B

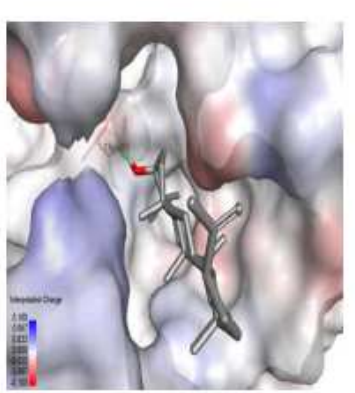

A

8

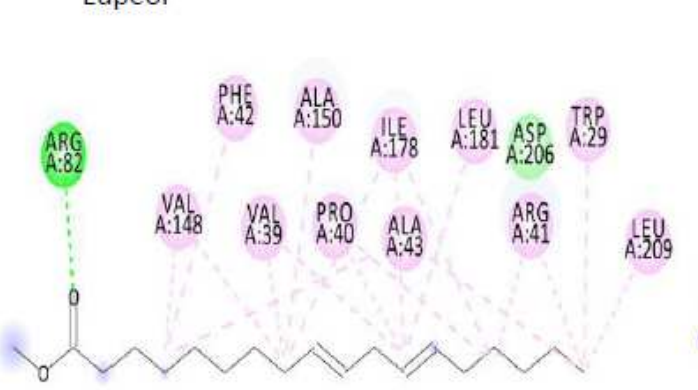

ARG
A:37

9,12-Octadecadienoic acid
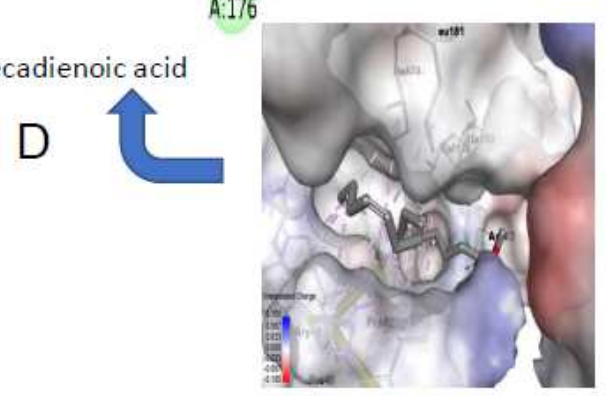

C
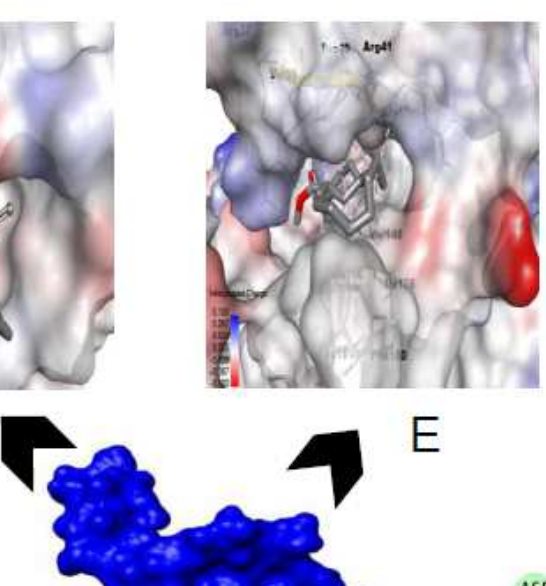

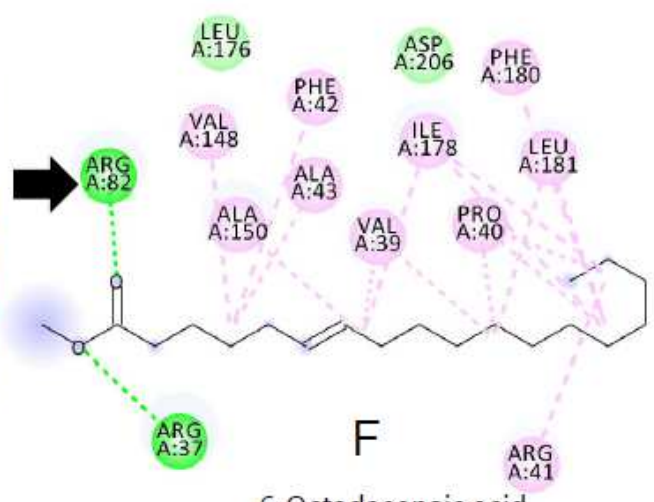

6-Octadecenoic acid

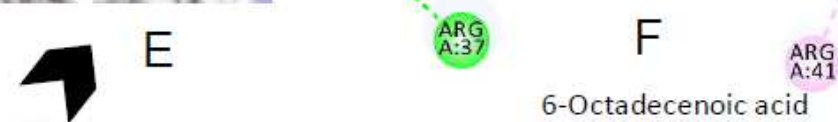

ASP

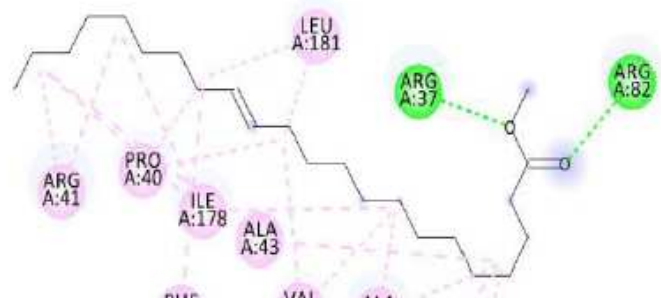
P. PHE

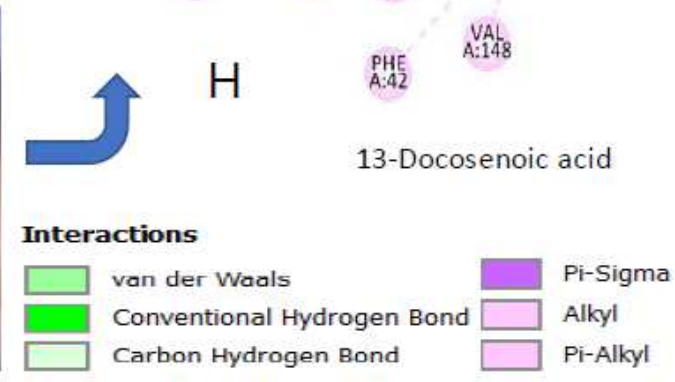

G

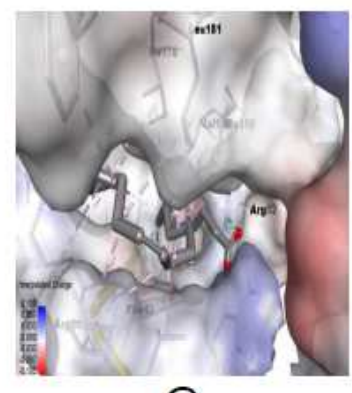

\section{Figure 6}

A. nilotica major chemical constituents inhibit APRT of L. donovani in silico (A) Lupeol blocking the binding pocket of APRT (PDB ID: 1QB7) enzyme. (B) 2D plot showing interactions between receptor and ligand. (C) 9,12-Octadecadienoic acid blocking the binding pocket of APRT (PDB ID: 1QB7) enzyme. (D) 2D plot showing interactions between receptor and ligand. (E) 6-Octadecenoic acid blocking the binding pocket of APRT (PDB ID: 1QB7) enzyme. (F) 2D plot showing interactions between receptor and ligand. (G) 13-Docosenoic acid blocking the binding pocket of APRT (PDB ID: 1QB7) enzyme. (H) 2D plot showing interactions between receptor and ligand.

\section{Supplementary Files}

This is a list of supplementary files associated with this preprint. Click to download.

- SupplementaryMaterials.pdf 